\title{
Consumption of Cuban Policosanol Improves Blood Pressure and Lipid Profile via Enhancement of HDL Functionality in Healthy Women Subjects: Randomized, Double-Blinded, and Placebo-Controlled Study
}

\author{
Kyung-Hyun Cho $\mathbb{D}^{1},{ }^{1,2,3}$ Suk-Jeong Kim, ${ }^{1,2,3}$ Dhananjay Yadav $\mathbb{D}^{1,2,3}$ Jae-Yong Kim, $^{1}$ \\ and Jae-Ryong Kim ${ }^{4}$ \\ ${ }^{1}$ Department of Medical Biotechnology, Yeungnam University, Gyeongsan 712-749, Republic of Korea \\ ${ }^{2}$ Research Institute of Protein Sensor, Yeungnam University, Gyeongsan 712-749, Republic of Korea \\ ${ }^{3}$ LipoLab, Yeungnam University, Gyeongsan 712-749, Republic of Korea \\ ${ }^{4}$ Department of Biochemistry and Molecular Biology, Smart-Aging Convergence Research Center, College of Medicine, \\ Yeungnam University, Daegu 705-717, Republic of Korea
}

Correspondence should be addressed to Kyung-Hyun Cho; chok@yu.ac.kr

Received 26 September 2017; Revised 3 December 2017; Accepted 18 December 2017; Published 16 April 2018

Academic Editor: Cristiana Caliceti

Copyright (c) 2018 Kyung-Hyun Cho et al. This is an open access article distributed under the Creative Commons Attribution License, which permits unrestricted use, distribution, and reproduction in any medium, provided the original work is properly cited.

\begin{abstract}
Policosanol has been reported to improve blood pressure, lipid profile, and HDL functionality via inhibition of cholesteryl ester transfer protein (CETP) both in vitro and in vivo in zebrafish and human models. However, there are limited reports and randomized, double-blinded trials on policosanol that could advocate the blood pressure-lowering effect in prehypertensive participants. Therefore, we performed in vitro, in vivo, and ex vivo experiments to provide more substantial and concrete data on the blood pressure-lowering effect of policosanol. Consumption of policosanol for 8 weeks enhanced plasma antioxidant activity. In the policosanol group, plasma total cholesterol (TC) and triglyceride (TG) levels were reduced up to $20 \%$ and $14 \%$, respectively, and HDL-C level was elevated up to 1.3 -fold compared to that at week 0 . TG/HDL-C and cholesteryl ester transfer protein (CETP) activities were reduced up to $36 \%$ and $20 \%$, respectively. Uptake of oxidized LDL in macrophages was reduced as oxidized species levels were reduced, and $\mathrm{HDL}_{2}$-associated paraoxonase activities were enhanced by $60 \%$ compared to those at week 0. Encapsulation of policosanol into reconstituted HDL (PCO-rHDL) enhanced cholesterol efflux activity and insulin secretion capacity. In conclusion, consumption of policosanol for 8 weeks in healthy female subjects resulted in lowered blood pressure and CETP activity via elevation of HDL/apoA-I contents and enhancement of HDL functionalities, including cholesterol efflux and insulin secretion. These functional enhancements of HDL can contribute to the prevention of aging-related diseases, hypertension, and stroke.
\end{abstract}

\section{Introduction}

It is well known that elevation of serum HDL-C levels is an effective strategy for suppressing the incidence of aging-related diseases such as cardiovascular disease (CVD), diabetes, and Alzheimer's disease [1]. In addition to HDL-C quantity, it has been firmly established that
HDL quality and functionality are more important in the suppression of aging-related diseases [2]. However, there has been no strategy involving the use of dietary foods or medicines in the elevation of HDL-C quantity and enhancement of HDL functionality except for aerobic exercise [3]. As a functional food, Cuban policosanol (PCO) was reported to elevate HDL-C levels in hypercholesterolemic 
rabbits and humans as well as reduce LDL-C levels and oxidation [4-6].

Policosanol enhances the beneficial functions of HDL and maximizes its antioxidant, antiglycation, and antiatherosclerotic activities along with inhibition of CETP activity [7-9]. These results suggest an association between policosanol activity and HDL functionality for enhancement of longevity. Reconstituted HDL (rHDL) containing policosanol (PCO-rHDL) was shown to induce upregulation of tissue regeneration activity in a zebrafish model [7] along with a lipid-lowering effect [8]. However, until now, the basic mechanism of policosanol has not been fully elucidated. One problematic hurdle preventing any investigation into the physiological functions of policosanol is its water insolubility in enzyme assay, cell-based assay, and in vivo animal systems. To overcome this, a policosanol mixture was assimilated into reconstituted HDL with apoA-I in order to investigate the physiological functions of policosanol in lipoprotein metabolism [7]. Policosanol in rHDL has potent antioxidant, antiglycation, and CETP inhibitory activities as well as tissue regeneration activity, especially upon integration into HDL. The physiological effect of policosanol was investigated in brain cells (neuroglioma) and hypercholesterolemic zebrafish. Nine weeks of policosanol consumption resulted in decreased serum TC and TG levels, increased HDL-C levels via CETP activity inhibition, and amelioration of fatty liver [8]. Kaup et al. previously reported that Egyptian rice bran extract, which is enriched with policosanol and $\gamma$-oryzanol, has an antidiabetic effect in rats [10].

We recently reported that daily consumption of policosanol by young smoker (YS, $n=7$ ) and middle-aged male participants (MN, $n=11)$ for 8 weeks resulted in a lowering of systolic blood pressure up to $4 \%$. The serum TG levels exhibited a reduction up to 28 and $26 \%$ from the baseline values in the young nonsmoker ( $\mathrm{YN}, n=7)$ and middle-aged participants. Nonetheless, the percentage of HDL-C in total cholesterol was elevated in all male participants (YN, 36\%; YS, 35\%; MN, 8\%) after 8 weeks of policosanol consumption [9]. Nonetheless, our previous report was a pilot study in a different group of participants and needed a more specific data that may suggest the efficacy of policosanol on blood pressure. Moreover, the study lacks an appropriate control.

Although there have been many conflict data and arguments about the cholesterol-lowering efficacy of policosanol [11, 12], a recent meta-analysis [13] of randomized controlled trials from 22 studies including 1886 subjects concluded that policosanol could significantly reduce total cholesterol and LDL-C and increase HDL-C. In spite of many reports having examined the efficacy of policosanol in human subjects and animal models, there has been no in vitro or in vivo study on HDL functionality such as enhancement of cholesterol efflux and antioxidant ability with individually purified lipoprotein by sequential density gradient ultracentrifugation rather than concentration measured in the serum sample. Therefore, we tested the physiological effects of policosanol consumption on blood pressure and HDL functionality in healthy Korean female subjects.

\section{Materials and Methods}

2.1. Policosanol and Encapsulation. Policosanol tablet $(10 \mathrm{mg})$ was obtained from Rainbow \& Nature Pty, Ltd (Thornleigh, NSW, Australia). Policosanol (sugar cane wax alcohol, SCWA) contains several alcohol chains of various lengths. Contents of higher aliphatic alcohols were $>90 \%$. The individual alcohols present in policosanol are 1-tetracosanol $\left(\mathrm{C}_{24} \mathrm{H}_{49} \mathrm{OH}\right.$; molecular weight (MW): $354.7 \mathrm{~m} \mu) \leq 2 \%$, 1-hexacosanol $\left(\mathrm{C}_{26} \mathrm{H}_{53} \mathrm{OH}\right.$; MW: $\left.382.4 \mathrm{~m} \mu\right)$ $\leq 4.5-10 \%$, 1-heptacosanol $\left(\mathrm{C}_{27} \mathrm{H}_{55} \mathrm{OH} ; \quad\right.$ MW: $\left.396.4 \mathrm{~m} \mu\right)$ $\leq 5 \%$, 1-octacosanol $\left(\mathrm{C}_{28} \mathrm{H}_{57} \mathrm{OH} ;\right.$ MW: $\left.410.5 \mathrm{~m} \mu\right) \leq 60$ 70\%, 1-nonacosanol $\left(\mathrm{C}_{29} \mathrm{H}_{59} \mathrm{OH} ; \mathrm{MW}: 424.8 \mathrm{~m} \mu\right) \leq 2 \%$, 1-triacontanol $\left(\mathrm{C}_{30} \mathrm{H}_{61} \mathrm{OH}\right.$; MW: $\left.438.5 \mathrm{~m} \mu\right) \leq 10-15 \%$, 1dotriacontanol $\left(\mathrm{C}_{32} \mathrm{H}_{65} \mathrm{OH}\right.$; MW: $\left.466.5 \mathrm{~m} \mu\right) \leq 3-8 \%$, and 1-tetratriacontanol $\left(\mathrm{C}_{34} \mathrm{H}_{69} \mathrm{OH}\right.$; MW: $\left.494.5 \mathrm{~m} \mu\right) \leq 2 \%$.

To overcome the insolubility of policosanol in aqueous isotonic buffer, we synthesized rHDL-containing PCO (PCO-rHDL). A rHDL-containing policosanol was synthesized according to our previous report [7] by the sodium cholate dialysis method using initial molar ratios of $95: 5: 1$ for POPC: cholesterol:apoA-I containing $0.5 \mu \mathrm{g}, 2.5 \mu \mathrm{g}$, or $5 \mu \mathrm{g}$ of policosanol.

2.2. Participants. We recruited healthy female volunteers who had prehypertension (systolic $120-139 \mathrm{mmHg}$, diastolic $80-89 \mathrm{mmHg}$ ). All volunteers were prescreened for eligibility for the following inclusion criteria: age 18-65 years who had prehypertension without any known endocrinological disorder. Heavy alcohol consumers ( $>30 \mathrm{~g} \mathrm{EtOH/day)} \mathrm{and} \mathrm{those}$ who consumed any prescribed drugs for hyperlipidemia, diabetes mellitus, or hypertension were excluded. All subjects had unremarkable medical records without prohibited drug use or history of systemic diseases. On the first visit day, all participants casted dice for randomized grouping. The description of the study is shown in Figure 1, and the recruited participants consumed policosanol for 8 weeks. We analyzed serum parameters from all participants who consumed policosanol daily ( $10 \mathrm{mg}$ tablet) or placebo for 8 weeks. Informed consent was obtained from all participants prior to commencement of the study, and the Institutional Review Board at Yeungnam University (Gyeongsan, South Korea) approved the protocol (IRB no. 7002016-A2016-021).

2.3. Study Design. This study was a double-blinded, randomized, and placebo-controlled trial with 8-week treatment periods. Subjects were instructed to take one tablet containing policosanol (10 $\mathrm{mg}$ of sugar cane wax alcohol) or placebo consisting of a dextrin and lactose mixture, manufactured in Cosmax Bio Inc. (Jecheon, Korea), per day. Other ingredients to make tablet are corn starch, cellulose, gelatin, stearic acid, and so on. All ingredients, the manufacturing process, and the facility were approved by Korean FDA.

All participants were instructed to avoid excess alcohol drinking (less than $30 \mathrm{~g}$ of EtOH per day). They were also instructed to avoid vigorous exercise (less than $30 \mathrm{~min}$ per day at $60-80 \%$ maximum capacity). If subjects had a 


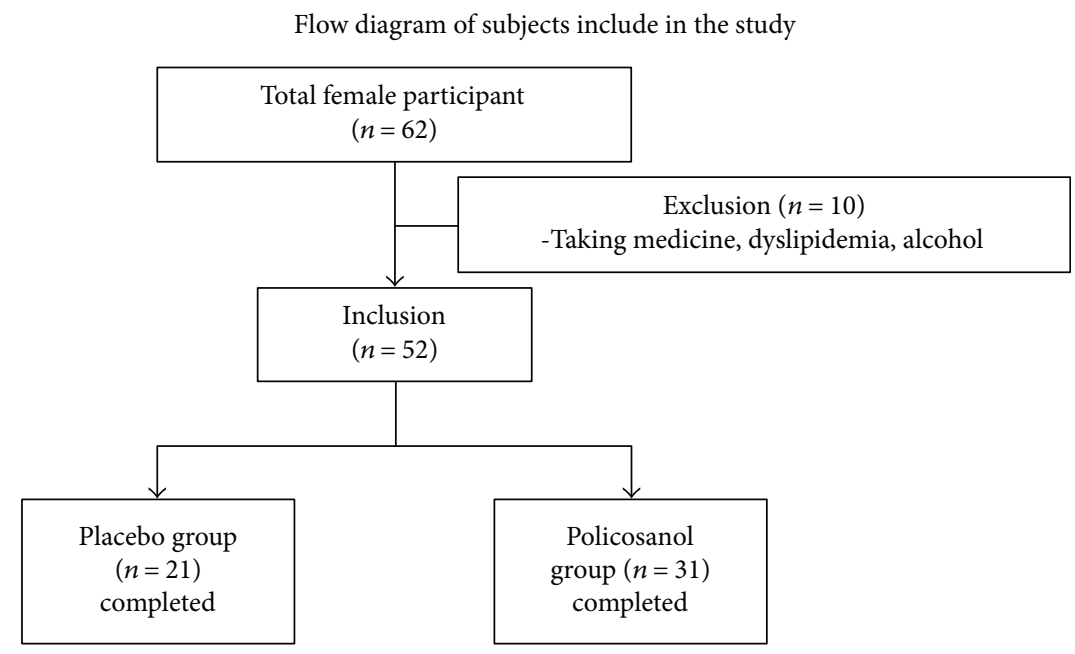

FIGURE 1: Design of study and participants. Inclusion criteria were normolipidemic, normoglycemic, and healthy subjects. Exclusion criteria were heavy alcohol drinkers $(30 \mathrm{~g}>$ day of EtOH), patients with endocrinological disorders, and those taking hyperlipidemic medicine.

sedentary lifestyle before enrollment, we recommended them to maintain their lifestyle during the consumption period to avoid bias due to excess exercise.

2.4. Anthropometric Analysis. Height, body weight, body mass index (BMI), total body fat (\%), total body fat mass $(\mathrm{kg})$, and visceral fat mass $(\mathrm{kg})$ of each participants were measured at the same time of the day at 4-week intervals using an X-Scan Plus II body composition analyzer (Jawon Medical, Gyeongsan, Korea).

2.5. Measurement of Blood Pressure. Blood pressure was measured each visit for three times, and the average was recorded at 4-week intervals using three methods. First, we used a digital blood pressure monitor (Omron HBP-9020, Kyoto, Japan). Second, a pulse wave analyzer, SphygmoCor system (AtCor Medical, Sydney, Australia), was used to measure brachial and aortic artery blood pressure. Third, a mercury sphygmomanometer was used for manual measurement by a licensed technician.

To diagnose hypertension, three different methods were employed in the current study to measure blood pressure based on the brachial and radial arteries. However, there exists a discrepancy in blood pressure measurement among these devices [14]. Instruments such as the Omron digital blood pressure device and mercury sphygmomanometer are commonly used in hospitals to estimate blood pressure. However, in epidemiological studies, focusing on central aortic blood pressure is advisable due to its various advantages over traditional blood pressure measurements. Aortic blood pressure is the pressure exerted on the heart and brain and is dissimilar to blood pressure in the limbs such as the arms. Central aortic blood pressure is more accurate and standardized for the diagnosis and management of hypertension compared to blood pressure measurements based on brachial arteries [15]. In comparing their predictive values for cardiovascular mortality, central blood pressure was shown to be better than brachial blood pressure [16]. Brown reported that measurement of blood pressure using a mercury sphygmomanometer or Omron digital machine is based on the brachial artery, which has a structure that is reportedly unaffected by hypertension [17]. To overcome these limitations, this study used three different types of methods for measuring blood pressure.

2.6. Measurement of Augmentation Index and Augmentation Pressure. Augmentation index, which is the difference between the second and first systolic peaks expressed as a percentage of the pulse pressure, is a measure of systemic arterial stiffness and wave reflection, as described previously [18]. A licensed technician trained in the technique and blinded to the characteristics of each subject performed measurements of augmentation pressure and augmentation index.

2.7. Plasma Analysis. Blood was obtained from the subjects following overnight fasting. Blood was collected using a vacutainer (BD Biosciences, Franklin Lakes, NJ, USA) containing EDTA (final concentration of $1 \mathrm{mM}$ ) at weeks 0 and 8 during intake of policosanol. Plasma was isolated by lowspeed centrifugation $(3000 \mathrm{~g})$ and stored at $-80^{\circ} \mathrm{C}$ until analysis. To analyze plasma, total cholesterol (TC), triglyceride (TG), high-density lipoprotein cholesterol (HDL-C), glucose, uric acid, aspartate aminotransferase (AST), and alanine aminotransferase (ALT) levels were measured using commercially available kits (Cleantech TS-S; Wako Pure Chemical, Osaka, Japan). Plasma aldosterone levels was measured by radioimmunoassay (RIA) using the instrument 1470-Gamma Counter (PerkinElmer) via Seegene Medical Foundation (Seoul, Korea).

2.8. Ferric Reducing Ability of Plasma Assay. The ferric reducing ability of plasma (FRAP) was determined using the method described by Benzie and Strain [19]. The antioxidant activities of individual HDL fractions $(20 \mu \mathrm{g}$ each in PBS) were estimated by measuring increases in absorbance induced by generated ferrous ions.

2.9. Characterization of Lipoproteins. Very low-density lipoprotein (VLDL, $d<1.019 \mathrm{~g} / \mathrm{mL}$ ), low-density lipoprotein 
(LDL, $1.019<d<1.063)$, high-density lipoprotein ${ }_{2}\left(\mathrm{HDL}_{2}\right.$, $1.063<d<1.125)$, and high-density lipoprotein ${ }_{3}\left(\mathrm{HDL}_{3}\right.$, $1.125<d<1.225$ ) were isolated from the individual plasma of each group via sequential ultracentrifugation [20], and the density was adjusted by addition of $\mathrm{NaCl}$ and $\mathrm{NaBr}$ in accordance with standard protocols. Samples were centrifuged for $22 \mathrm{hr}$ at $10^{\circ} \mathrm{C}$ and $100,000 \mathrm{~g}$ using a Himac CP100NX (Hitachi, Tokyo, Japan) at the Instrumental Analysis Center of Yeungnam University. To measure lipoproteins, total cholesterol (TC) and triglyceride (TG) levels were analyzed using commercially available kits (Cleantech TS-S; Wako Pure Chemical, Osaka, Japan). Protein concentrations of lipoproteins were calculated via Lowry protein assay, as modified by Markwell et al. [21].

To estimate the degree of oxidation in lipoprotein, the concentration of oxidized species in lipoproteins was determined by the thiobarbituric acid reactive substance (TBARS) assay method using malondialdehyde as a standard [22]. To differentiate the extent of glycation between the groups, advanced glycation end products (AGEs) in lipoproteins were determined from reading fluorometric intensities at $370 \mathrm{~nm}$ (excitation) and $440 \mathrm{~nm}$ (emission), as described previously [23], using a spectrofluorometer LS55 (PerkinElmer, Shelton, CT, USA) with the WinLab software package (version 4.0).

2.10. Cholesteryl Ester Transfer Protein Assay. A rHDLcontaining apoA-I and cholesteryl oleate were synthesized in accordance with the method described by Cho [24] using trace amounts of $\left[{ }^{3} \mathrm{H}\right]$-cholesteryl oleate (TRK886, $3.5 \mu \mathrm{Ci} / \mathrm{mg}$ of apoA-I; GE Healthcare). Briefly, lipids (POPC, cold cholesteryl oleate, and $\left[{ }^{3} \mathrm{H}\right]$-cholesteryl oleate) were mixed in a glass vial and gently vortexed, followed by drying under a $\mathrm{N}_{2}$ gas stream at $37^{\circ} \mathrm{C}$. After drying, the lipids were dispersed by addition of TBS with slight agitation. Phospholipid bilayer formation was facilitated by addition of sodium cholate and apoA-I. After extensive dialysis for $24 \mathrm{hr}$ to remove cholate, $\left[{ }^{3} \mathrm{H}\right]$-CE-rHDL was recovered and characterized by scintillation counting and protein determination.

$\left[{ }^{3} \mathrm{H}\right]$-CE-rHDL was immobilized using $\mathrm{CNBr}$-activated Sepharose 4B resin (Amersham Biosciences) for easy separation after the reaction, in accordance with the manufacturer's instructions. CE transfer reaction was performed in $300 \mu \mathrm{L}$ reaction mixtures containing human serum $(20 \mu \mathrm{L})$ or $\mathrm{HDL}_{3}(20 \mu \mathrm{L}, 2 \mathrm{mg} / \mathrm{mL})$ as a cholesteryl ester transfer protein (CETP) source, $\left[{ }^{3} \mathrm{H}\right]$-rHDL-agarose $(20 \mu \mathrm{L}, 0.25 \mathrm{mg} / \mathrm{mL})$ as a CE donor, and human LDL $(20 \mu \mathrm{L}, 0.25 \mathrm{mg} / \mathrm{mL})$ as a CE acceptor. After incubation at $37^{\circ} \mathrm{C}$, the reaction was halted via brief centrifugation $(10,000 \mathrm{~g})$ for $3 \mathrm{~min}$ at $4^{\circ} \mathrm{C}$. The supernatant containing the $\mathrm{CE}$ acceptor $(150 \mu \mathrm{L})$ was then subjected to scintillation counting, and percentage transfer of $\left[{ }^{3} \mathrm{H}\right]-\mathrm{CE}$ from $\left[{ }^{3} \mathrm{H}\right]$-rHDL to LDL was calculated.

2.11. Paraoxonase Assay. Paraoxonase-1 (PON-1) activity was determined by measuring the initial velocity of $p$-nitrophenol production at $37^{\circ} \mathrm{C}$ based on its absorbance at $405 \mathrm{~nm}$ (microplate reader, Bio-Rad model 680; Bio-Rad, Hercules, CA, USA), as described previously [25] with slight modification [26]. Prior to the measurement, HDL was thoroughly dialyzed against PBS to eliminate EDTA.

2.12. LDL Oxidation. Oxidized LDL (oxLDL) was obtained by incubation of the $\mathrm{LDL}$ fraction with $\mathrm{CuSO}_{4}$ (final concentration of $10 \mu \mathrm{M}$ ) for $4 \mathrm{hr}$ at $37^{\circ} \mathrm{C}$. oxLDL was then filtered through a $0.22 \mu \mathrm{m}$ filter (Millex; Millipore, Bedford, MA) and measured by thiobarbituric acid reactive substances (TBARS) assay to determine the extent of oxidation [22].

2.13. Phagocytosis of LDL into Macrophages. THP-1 cells, a human monocytic cell line, were obtained from the American Type Culture Collection (ATCC, TIB-202 ${ }^{\mathrm{TM}}$, Manassas, VA, USA) and maintained in RPMI 1640 medium (HyClone, Logan, UT) supplemented with 10\% fetal bovine serum until needed. Cells below 20 passages were incubated in medium containing phorbol 12-myristate 13-acetate (PMA, $150 \mathrm{nM}$ ) in 24 -well plates for $48 \mathrm{hr}$ at $37^{\circ} \mathrm{C}$ in a humidified incubator $\left(5 \% \mathrm{CO}_{2}, 95 \%\right.$ air $)$ in order to induce differentiation into macrophages. Differentiated and adherent macrophages were then rinsed with warm PBS, followed by incubation with $450 \mu \mathrm{L}$ of fresh RPMI 1640 medium containing $0.1 \% \mathrm{FBS}$ and $50 \mu \mathrm{g}$ of each LDL ( $1 \mathrm{mg}$ of protein $/ \mathrm{mL}$ in PBS) for $48 \mathrm{hr}$ at $37^{\circ} \mathrm{C}$ in a humidified incubator. After incubation, cells were washed with PBS three times and then fixed in $4 \%$ paraformaldehyde for $10 \mathrm{~min}$. Next, fixed cells were stained with Oil Red O staining solution $(0.67 \%)$ and washed with distilled water. THP-1 macrophage-derived foam cells were then observed and photographed using a Nikon Eclipse TE2000 microscope (Tokyo, Japan) at 400x magnification, as in our previous report [27]. Cell medium $(0.2 \mathrm{~mL})$ was then analyzed by the TBARS assay to evaluate changes in the levels of oxidized species using a malondialdehyde (MDA) standard.

2.14. Antiatherogenic Activity of $H D L_{3}$. Differentiated and adherent macrophages were then washed with warm PBS and incubated with $400 \mu \mathrm{L}$ of fresh RPMI 1640 medium containing $0.1 \%$ fetal bovine serum, $50 \mu \mathrm{g}$ of oxLDL ( $1 \mathrm{mg}$ of protein $/ \mathrm{mL}$ in PBS), and $30 \mu \mathrm{g}$ of $\mathrm{HDL}_{3}(2 \mathrm{mg}$ of protein $/ \mathrm{mL}$ in PBS) from each group for $48 \mathrm{hr}$ at $37^{\circ} \mathrm{C}$ in a humidified incubator. After incubation, cells were stained with Oil Red O solution (0.67\%) to visualize the amount of lipid species in cells. THP-1 macrophage-derived foam cells were then observed and photographed using a Nikon Eclipse TE2000 microscope (Tokyo, Japan) at 400x magnification. Quantification area was carried out via computer-assisted morphometry using Image-Pro Plus software (version 4.5.1.22, Media Cybernetics, Bethesda, MD).

2.15. In Vitro Cholesterol Efflux. THP-1 cells were incubated in medium containing phorbol 12-myristate 13acetate (PMA, $150 \mathrm{nM})$ on a plate for $48 \mathrm{hr}$ at $37^{\circ} \mathrm{C}$ in a humidified incubator to induce differentiation into macrophages. The macrophages were treated with radiolabeled cholesterol $\left(0.1 \mu \mathrm{Ci}\right.$ of $\left[{ }^{3} \mathrm{H}\right]$-cholesterol $)$ in RPMI 1640 medium (HyClone, Logan, UT) containing $1 \%$ fetal bovine serum (HyClone, Logan, UT) per well $(0.5 \mathrm{~mL})$ for $48 \mathrm{hr}$. The medium containing the isotope was saved and replaced with fresh media containing $0.3 \mathrm{mM} 8$-(4-chlorophenylthio)- 
cyclic adenosine monophosphate (cAMP, Cat. No. C3912, Sigma-Aldrich, St. Louis, MO) for upregulation of cellular cholesterol pump (adenosine triphosphate- (ATP-) binding cassette $(A B C)$ transporter-1, ABCA-1) for $18 \mathrm{hr}$. After removal of media containing cAMP, human $\mathrm{HDL}_{3}(28 \mu \mathrm{g}$ of apoA-I) or rHDL containing policosanol was added and incubated with serum-free media $(0.5 \mathrm{~mL})$ for $24 \mathrm{hr}$. Subsequently, the cell medium $(0.5 \mathrm{~mL})$ in individual wells was collected in a $1.7 \mathrm{~mL}$ tube. Cells were rinsed with PBS three times and dissolved in $0.2 \mathrm{~mL}$ of RIPA buffer $(50 \mathrm{mM}$ Tris$\mathrm{HCl}[\mathrm{pH} 8.0], 150 \mathrm{mM} \mathrm{NaCl}, 5 \mathrm{mM}$ EDTA [pH 8.0], $1 \%$ NP- $40,0.5 \%$ sodium deoxycholate, and $0.1 \%$ sodium dodecyl sulfate) for cell lysis. An aliquot of the cell lysate $(0.1 \mathrm{~mL})$ was mixed with scintillation cocktail $(3 \mathrm{~mL})$ to quantify the isotope amount of cholesterol taken up into cells. After scintillation counting of $\left[{ }^{3} \mathrm{H}\right]$-cholesterol in cells and medium, the amount of effluxed cholesterol from cells was calculated using the following formula [28]:

$$
\begin{aligned}
\% \text { Cholesterol efflux } & =\frac{(\text { media counts } \times \text { dilution factor })}{(\text { media count } \times \text { dilution factor })+(\text { cell lysis count } \times \text { dilution factor })} \times 100, \\
\% \text { Net ef flux } & =\% \text { cholesterol efflux }\left(\text { with } \mathrm{HDL}_{3}\right)-\% \text { blank efflux }\left(\text { without } \mathrm{HDL}_{3}\right) .
\end{aligned}
$$

2.16. ELISA and Western Blot. To evaluate CETP activity in plasma, each well of a polystyrene microplate (no. 3590; Corning Inc., Corning, NY, USA) was coated with antihuman CETP rabbit antibody (ab19012; Abcam, Cambridge, $\mathrm{UK})$ at a concentration of $0.25 \mu \mathrm{g} / \mathrm{mL}$ and incubated overnight at $4^{\circ} \mathrm{C}$. Equally, diluted serum samples were incubated for $2 \mathrm{hr}$ at room temperature. After extensive washing, antihuman CETP mouse antibody (ab2726; Abcam, $1 \mu \mathrm{g} / \mathrm{mL}$ ) was treated and incubated for $2 \mathrm{hr}$ at room temperature. To develop the color reaction, anti-mouse IgG antibody (ab6728; Abcam, $0.5 \mu \mathrm{g} / \mathrm{mL}$ conjugated with horseradish peroxidase) was added. For color development, $3,3^{\prime}, 5,5^{\prime}$ tetramethylbenzidine (TMB) substrate solution (Cat. No. 555214; BD Biosciences, Franklin Lakes, NJ, USA) was treated and quantified using a VICTOR X4 microplate reader (Perkin Elmer, Waltham, MA).

Apolipoprotein/lipoprotein constitution was compared via sodium dodecyl sulfate-polyacrylamide gel electrophoresis (SDS-PAGE) with identical protein loading quantities ( $5 \mu \mathrm{g}$ of total protein per lane) from cell lysate via immunodetection. Anti-human apoA-I antibody (ab7613), antiABCA1 antibody (ab24261), and anti-GAPDH antibody (ab6672) were purchased from Abcam (Cambridge, UK). The relative band intensities were compared via band scanning using a Gel Doc ${ }^{\circledR}$ XR (Bio-Rad, Hercules, CA) with Quantity One software, version 4.5.2. We used simple basic steps to measure the band intensity by densitometry analysis. Blot images are imported into the Quantity One software, and then the contrast was adjusted in such a manner that the bands were clearly noticeable on the blot image. The area around each band was selected; further, the background intensity was subtracted from the blot image. The bands were then outlined by drawing a boundary around it; band intensities were exported in excel format for further analysis.

2.17. Insulin Secretion Assay. A rat insulinoma cell line (INS-1), kindly provided by K-C. Won (Department of Internal Medicine, College of Medicine, Yeungnam University), was maintained at $37^{\circ} \mathrm{C}$ in RPMI 1640 medium (Gibco BRL, Grand Island, NY, USA) containing $11.1 \mathrm{mmol} / \mathrm{L}$ of glucose and $2 \mathrm{mmol} / \mathrm{L}$ of L-glutamine. The medium was supplemented with $10 \% \mathrm{FBS}, 1 \mathrm{mmol} / \mathrm{L}$ of pyruvate, $10 \mathrm{mmol} / \mathrm{L}$ of HEPES, $50 \mu \mathrm{mol} / \mathrm{L}$ of $\beta$-mercaptoethanol, 100 units $/ \mathrm{mL}$ of penicillin, and $100 \mu \mathrm{g} / \mathrm{mL}$ of streptomycin (INS-1 medium), as in our previous report [29]. INS-1 cells were incubated at $37^{\circ} \mathrm{C}$ in the presence or absence of PCOrHDL or plasma HDL. Incubations were carried out under low (final concentration of $2.8 \mathrm{mM}$ ) or high glucose concentration (final concentration of $25 \mathrm{mM}$ ) in culture medium, as previously reported [30]. After incubation, insulin secretion was determined using a radioimmunoassay kit (rat insulin RI-13K; Millipore, Billerica, MA, USA), according to the manufacturer's recommendation.

2.18. Electron Microscopy. Transmitted electron microscopy (TEM) was performed with a Hitachi electron microscope (model H-7600; Ibaraki, Japan) operated at $80 \mathrm{kV}$, as in our previous reports [31]. VLDL, LDL, and HDL were negatively stained with $1 \%$ sodium phosphotungstate $(\mathrm{pH} 7.4)$ with a final apolipoprotein concentration of $0.3 \mathrm{mg} / \mathrm{mL}$ in TBS.

2.19. Data Analysis. All data are expressed as the mean \pm SD from the three independent experiments with duplicate samples. Data comparisons were carried out by Student's $t$-test using the SPSS program (version 14.0; SPSS Inc., Chicago, IL, USA). The differences between the means were assessed using Duncan's multiple-range test. Statistical significance was defined as $p<0.05$.

\section{Results}

3.1. Changes in Body Composition. After 8 weeks of policosanol consumption, both groups had the same BMI. However, total body fat mass decreased up to $12 \%$ in the policosanol group, whereas the control group showed almost no change in body fat mass, as shown in Table 1. For fat distribution, visceral fat mass was reduced more than subcutaneous fat mass up to $20 \%$ in the policosanol group.

3.2. Blood Pressure. Based on the three measurements, the policosanol group showed significantly reduced average 
TABLE 1: Change of blood pressure and plasma profile after 8 weeks consumption.

\begin{tabular}{|c|c|c|c|c|}
\hline \multirow{2}{*}{ Age } & \multicolumn{2}{|c|}{$\begin{array}{c}\text { Placebo }(n=21) \\
31 \pm 16\end{array}$} & \multicolumn{2}{|c|}{$\begin{array}{c}\text { Policosanol }(n=31) \\
31 \pm 15\end{array}$} \\
\hline & Week 0 & Week 8 & Week 0 & Week 8 \\
\hline \multicolumn{5}{|l|}{ Body composition } \\
\hline BMI & $21 \pm 3$ & $21 \pm 3$ & $21 \pm 4$ & $21 \pm 4$ \\
\hline Total body fat (kg) & $13.5 \pm 3$ & $13.1 \pm 3$ & $15.2 \pm 4$ & $13.8 \pm 4^{*}$ \\
\hline Percentage of body fat (\%) & $24 \pm 5$ & $23 \pm 6$ & $25 \pm 6$ & $23 \pm 5$ \\
\hline Subcutaneous fat (kg) & $11.9 \pm 2.1$ & $11.7 \pm 2.4$ & $13.6 \pm 3.3$ & $12.5 \pm 3.0$ \\
\hline Visceral fat $(\mathrm{kg})$ & $1.3 \pm 0.4$ & $1.4 \pm 0.4$ & $1.5 \pm 0.5$ & $1.2 \pm 0.4^{*}$ \\
\hline \multicolumn{5}{|l|}{ Blood pressure $(\mathrm{mmHg})$} \\
\hline \multicolumn{5}{|l|}{ SphygmoCor XCEL } \\
\hline Systolic & $133 \pm 14$ & $126 \pm 8$ & $131 \pm 10$ & $118 \pm 14$ \\
\hline Diastolic & $87 \pm 10$ & $85 \pm 8$ & $82 \pm 9$ & $75 \pm 7$ \\
\hline \multicolumn{5}{|l|}{ Omron blood pressure monitor } \\
\hline Systolic & $131 \pm 16$ & $129 \pm 9$ & $130 \pm 10$ & $119 \pm 8$ \\
\hline Diastolic & $86 \pm 11$ & $85 \pm 7$ & $83 \pm 8$ & $67 \pm 7^{*}$ \\
\hline \multicolumn{5}{|l|}{ Mercury sphygmomanometer } \\
\hline Systolic & $131 \pm 9$ & $125 \pm 8$ & $129 \pm 8$ & $116 \pm 12^{*}$ \\
\hline Diastolic & $84 \pm 6$ & $83 \pm 5$ & $84 \pm 8$ & $72 \pm 8^{*}$ \\
\hline \multicolumn{5}{|l|}{ Average blood pressure } \\
\hline Systolic & $132 \pm 12$ & $127 \pm 7$ & $130 \pm 7$ & $117 \pm 14^{*}$ \\
\hline Diastolic & $86 \pm 9$ & $84 \pm 6$ & $83 \pm 8$ & $72 \pm 8^{*}$ \\
\hline Augmentation index (AI) & $17 \pm 3$ & $16 \pm 3$ & $16 \pm 3$ & $7 \pm 1^{*}$ \\
\hline Augmentation pressure (AP) & $7 \pm 1$ & $5 \pm 1$ & $7 \pm 2$ & $2 \pm 0^{*}$ \\
\hline \multicolumn{5}{|l|}{ Plasma profile } \\
\hline $\mathrm{TC}(\mathrm{mg} / \mathrm{dL})$ & $195 \pm 22$ & $201 \pm 21$ & $180 \pm 14$ & $146 \pm 10^{*}$ \\
\hline $\mathrm{TG}(\mathrm{mg} / \mathrm{dL})$ & $84 \pm 17$ & $92 \pm 20$ & $83 \pm 16$ & $72 \pm 12^{*}$ \\
\hline $\mathrm{HDL}-\mathrm{C}(\mathrm{mg} / \mathrm{dL})$ & $42 \pm 3$ & $45 \pm 4$ & $42 \pm 4$ & $53 \pm 8^{* *}$ \\
\hline$\% \mathrm{HDL}-\mathrm{C}$ & $21 \pm 3$ & $22 \pm 3$ & $23 \pm 2$ & $36 \pm 4^{* *}$ \\
\hline TG/HDL-C & $2.0 \pm 0.6$ & $2.1 \pm 0.6$ & $2.0 \pm 0.2$ & $1.4 \pm 0.1^{*}$ \\
\hline Calculated LDL-C (mg/dL) & $138 \pm 22$ & $137 \pm 20$ & $125 \pm 11$ & $81 \pm 7^{*}$ \\
\hline Glucose (mg/dL) & $87 \pm 5$ & $89 \pm 5$ & $91 \pm 6$ & $83 \pm 5$ \\
\hline CETP activity (\% CE transfer) & $38 \pm 4$ & $40 \pm 4$ & $39 \pm 5$ & $31 \pm 4^{*}$ \\
\hline CETP amount $(\mu \mathrm{g} / \mathrm{mL})$ & $1.9 \pm 0.2$ & $1.9 \pm 0.2$ & $2.0 \pm 0.2$ & $1.5 \pm 0.1$ \\
\hline Uric acid (mg/dL) & $6.7 \pm 1.4$ & $6.5 \pm 2.4$ & $6.6 \pm 0.8$ & $5.3 \pm 1.2^{*}$ \\
\hline Aldosterone (ng/dL) & $19 \pm 7$ & $25 \pm 8$ & $38 \pm 10$ & $23 \pm 6^{*}$ \\
\hline
\end{tabular}

AU: arbitrary unit; BP: blood pressure; BMI: body mass index; CETP: cholesteryl ester transfer protein; HDL-C: high-density lipoprotein cholesterol; TC: total cholesterol; TG: triglyceride; ${ }^{*} p<0.05$; versus $0-8$ weeks in each group.

systolic and diastolic blood pressure levels up to $10 \%$ and $14 \%$, respectively, whereas the control group showed similar blood pressure levels during 8 weeks of consumption. The policosanol group showed a significant reduction of augmentation index (AI) and augmentation pressure (AP) up to $57 \%$ and $72 \%$, respectively, whereas the control group showed no change after consumption (Table 1).

3.3. Plasma Lipid Profile and CETP Activity. As shown in Table 1, the policosanol group showed $19 \%$ and $14 \%$ reductions in TC and TG levels, respectively, at week 8 compared with week 0 , whereas the control group showed no difference. Plasma HDL-C level and percentage of HDL-C in TC were significantly elevated in the policosanol group up to 1.3 -fold and 1.6-fold, respectively, compared with those at week 0 . Furthermore, the calculated ratio of the TG/HDL-C level in the policosanol group was reduced to 1.4 after 8 weeks, whereas the control group showed no change (around 2.1). The calculated LDL-C level was also reduced in the policosanol group by $35 \%$, whereas the control group showed no change. Before policosanol consumption (at week 0), all groups showed relatively high CETP activity (around 38\% 


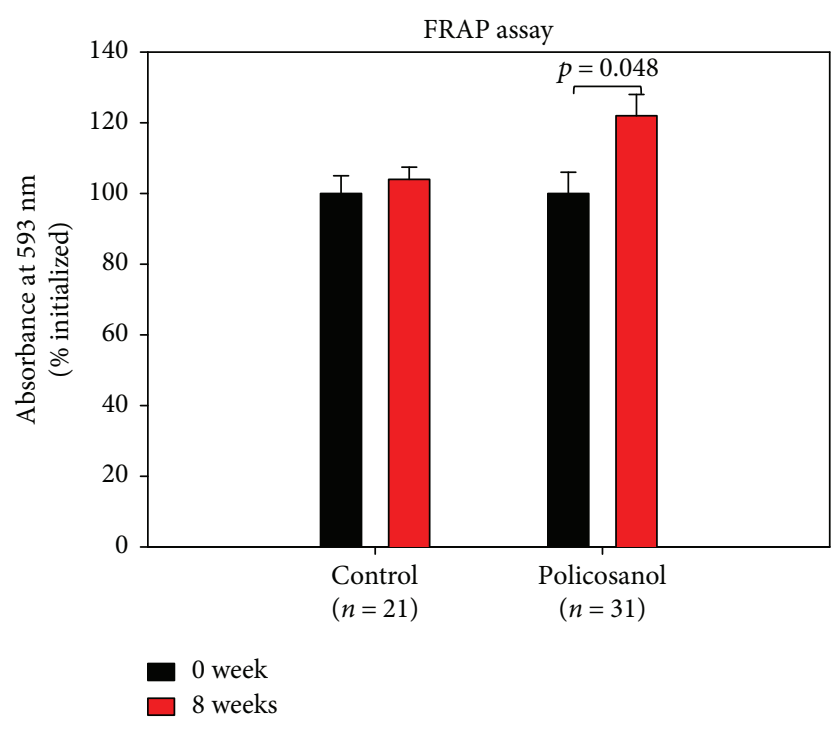

(a)

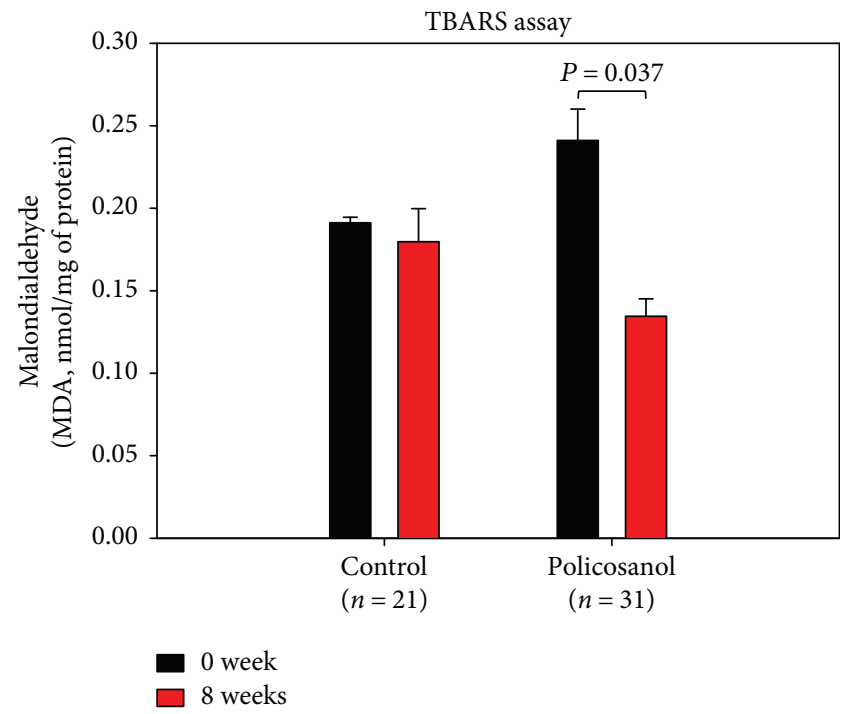

(b)

FIgURE 2: Changes in antioxidant ability and extent of oxidized species in serum upon policosanol consumption (bar represents the standard deviation of the mean). (a) Ferric ion reduction ability of serum $(0.05 \mathrm{~mL})$. (b) Determination of oxidized species using the thiobarbituric acid reactive substance method in serum $(0.1 \mathrm{~mL})$.

CE transfer). After 8 weeks, the policosanol group showed a significant reduction in CETP activity (around 31\% CE transfer), whereas the control group showed no change. In addition, the serum CETP amount was reduced in the policosanol group up to $25 \%$ compared with that at week 0 , whereas the placebo group showed no change. There was no significant change in glucose level in both groups from weeks 0 to 8 . Uric acid and aldosterone levels were significantly reduced in the participants who consumed policosanol for 8 weeks ( $10 \mathrm{mg}$ per day). However, there were no significant changes in uric acid and aldosterone in the placebo group after 8 weeks.

3.4. Serum Antioxidant Activity. The ferric ion reduction ability of plasma was elevated by $22 \%$ in the policosanol group after 8 weeks of consumption, as shown in Figure 2(a), whereas the control group showed no difference over 8 weeks. Malondialdehyde content also significantly decreased up to $50 \%$ after 8 weeks of policosanol consumption compared with that at week 0 (Figure 2(b)). The serum uric acid level was reduced by $20 \%$ in the policosanol group after 8 weeks of consumption, whereas the control group showed no change (Table 1).

3.5. Antioxidative Extent of Lipoproteins. After 8 weeks of policosanol consumption, LDL from the policosanol group showed slower electromobility following cupric ionmediated oxidation and agarose electrophoresis, as shown in Figure 3(a), whereas LDL from the control group showed faster electromobility. Without cupric ion treatment, all LDL showed similar electromobility, although LDL from the policosanol group after 8 weeks showed the slowest electromobility suggesting less production of negatively charged molecules and less fragmentation of apoB in LDL. However, the oxidized LDL moved faster to the cathode position because of the high negative charge and fragmentation of apoB (Figure 3(a)). Quantification of oxidized species using the TBARS method revealed that the policosanol group showed a significantly reduced malondialdehyde (MDA) content (up to $30 \%$ less) after 8 weeks, whereas the control group showed no change (Figure 3(b)). After policosanol consumption, PON activities for $\mathrm{HDL}_{2}$ and $\mathrm{HDL}_{3}$ in the policosanol group were elevated by $14 \%$ and $38 \%$, respectively, compared to those of the control group, as shown in Figure 4.

3.6. Glycation Extent of Lipoproteins. After 8 weeks of policosanol consumption, the policosanol group showed a significantly lowered glycation extent in all lipoprotein fractions, as shown in Figure 5(a). For VLDL and LDL, the policosanol group showed $43 \%$ and $39 \%$ less production of advanced glycation end products (AGEs) compared to the control group. For $\mathrm{HDL}_{2}$ and $\mathrm{HDL}_{3}$, the policosanol group showed $25 \%$ and $38 \%$ less production of AGEs, respectively, than the control group.

Protein content was detected in lipoprotein species, as shown in Figure 5(b). For VLDL, the policosanol group showed $20 \%$ less protein content than the control group did, whereas protein content in LDL was similar between the groups. However, protein contents in $\mathrm{HDL}_{2}$ and $\mathrm{HDL}_{3}$ increased in the policosanol group by 1.3- and 1.2-fold, respectively, compared to the control.

3.7. Enhanced Antiatherosclerotic Activity of $\mathrm{HDL}_{3}$ in Policosanol Group. As shown in Figures 6(a) and 6(b), oxLDL was easily taken up into macrophages, as evidenced by Oil Red $\mathrm{O}$ staining, and $\mathrm{HDL}_{3}$ from the control group resulted in $30 \%$ inhibition of phagocytosis. Interestingly, $\mathrm{HDL}_{3}$ from the policosanol group resulted in $70 \%$ reduction of phagocytosis, which was 2.4-fold greater than that of the control 

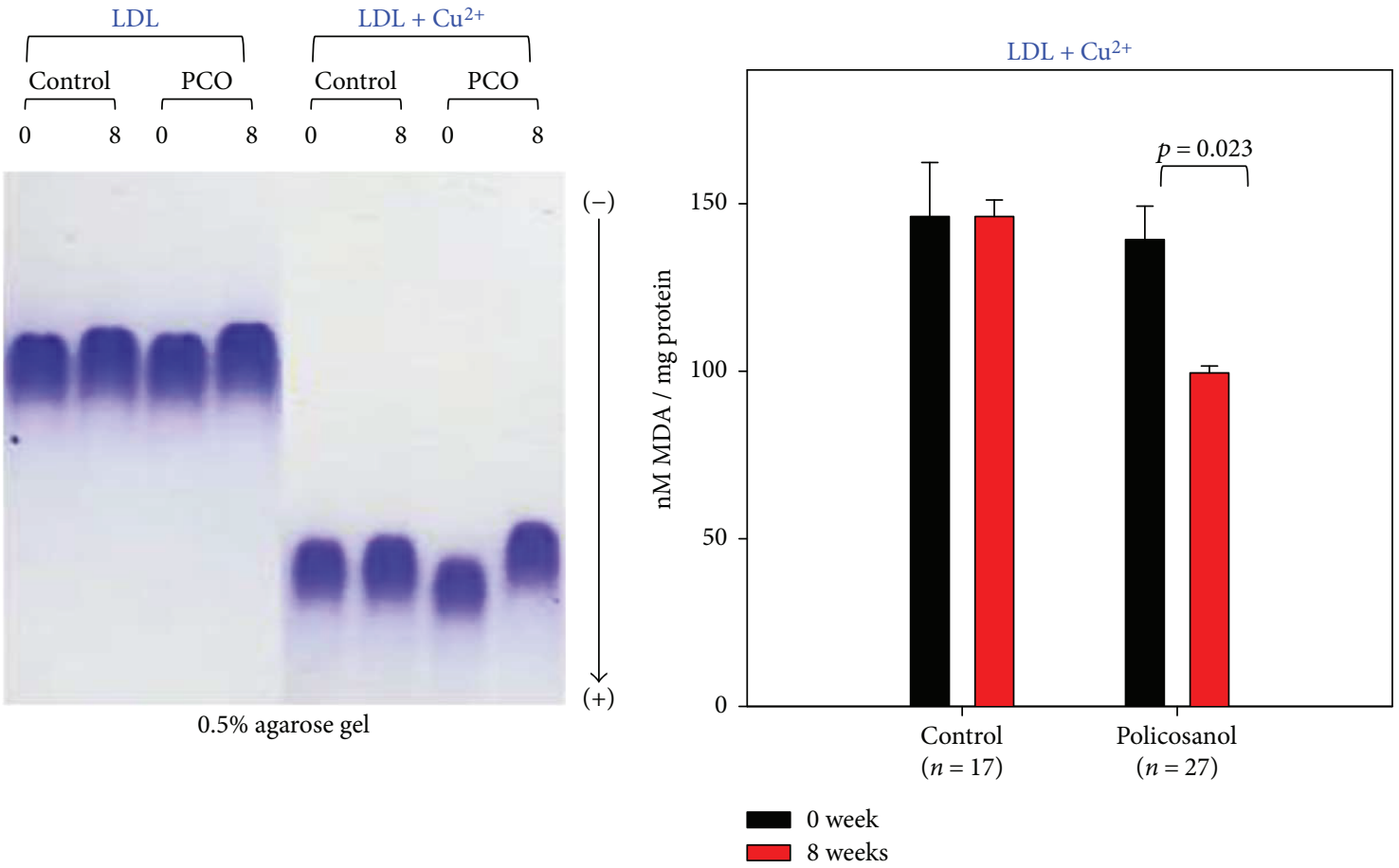

(a)

(b)

FIgURE 3: Comparison of LDL oxidation extent during policosanol consumption. (a) Comparison of electromobility of LDL between weeks 0 and 8 with or without cupric ion on a $0.5 \%$ agarose gel. (b) Determination of oxidized species using the thiobarbituric acid reactive substance method in LDL ( $1 \mathrm{mg}$ of protein) in native state at weeks 0 and 8 (bar represents the standard deviation of the mean).

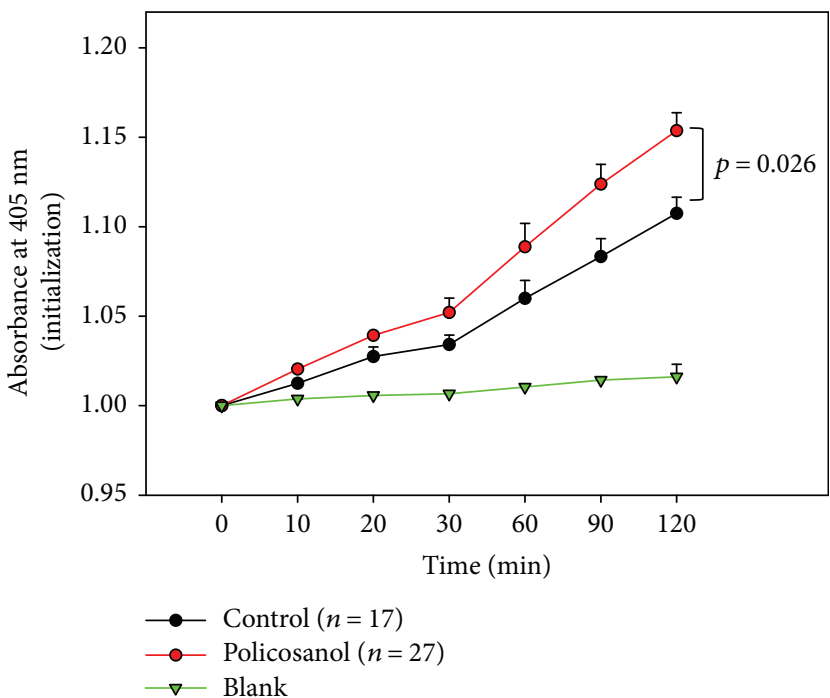

(a) $\mathrm{HDL}_{2}-\mathrm{PON}$

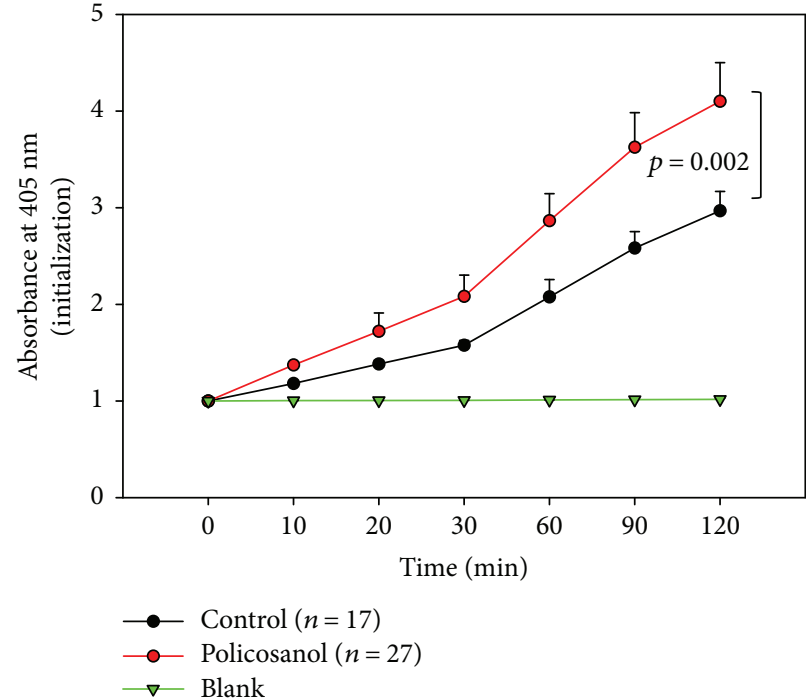

(b) $\mathrm{HDL}_{3}-\mathrm{PON}$

FIgure 4: Changes in activity of paraoxonase in HDL at 8 weeks after policosanol consumption. Error bars indicate the SD from three independent experiments with duplicate samples. (a) Equally diluted $\mathrm{HDL}_{2}(20 \mathrm{~mL}, 2 \mathrm{mg} / \mathrm{mL})$ was added to $230 \mathrm{~mL}$ of paraoxon-ethyl (Sigma Cat. No. D-9286) containing solution ( $90 \mathrm{mM}$ Tris- $\mathrm{HCl} / 3.6 \mathrm{mM} \mathrm{NaCl} / 2 \mathrm{mM} \mathrm{CaCl}_{2}$ [pH 8.5]). (b) Equally diluted $\mathrm{HDL}_{3}$ (20 mL, $2 \mathrm{mg} / \mathrm{mL}$ ) was added to $230 \mathrm{~mL}$ of paraoxon-ethyl (Sigma Cat. No. D-9286) containing solution $(90 \mathrm{mM} \mathrm{Tris-} \mathrm{HCl} / 3.6 \mathrm{mM} \mathrm{NaCl} / 2 \mathrm{mM}$ $\mathrm{CaCl}_{2}(\mathrm{pH} 8.5)$ ) (bar represents the standard deviation of the mean).

group. Quantification of oxidized species in cell culture media showed that oxLDL treatment resulted in the highest level of MDA (around $4.5 \mu \mathrm{M}$ ) in media. $\mathrm{HDL}_{3}$ from the policosanol group resulted in the lowest MDA level (around $2.1 \mu \mathrm{M})$ in media, whereas control cells showed a $2.9 \mu \mathrm{M}$ MDA level (Figure 6(c)). 


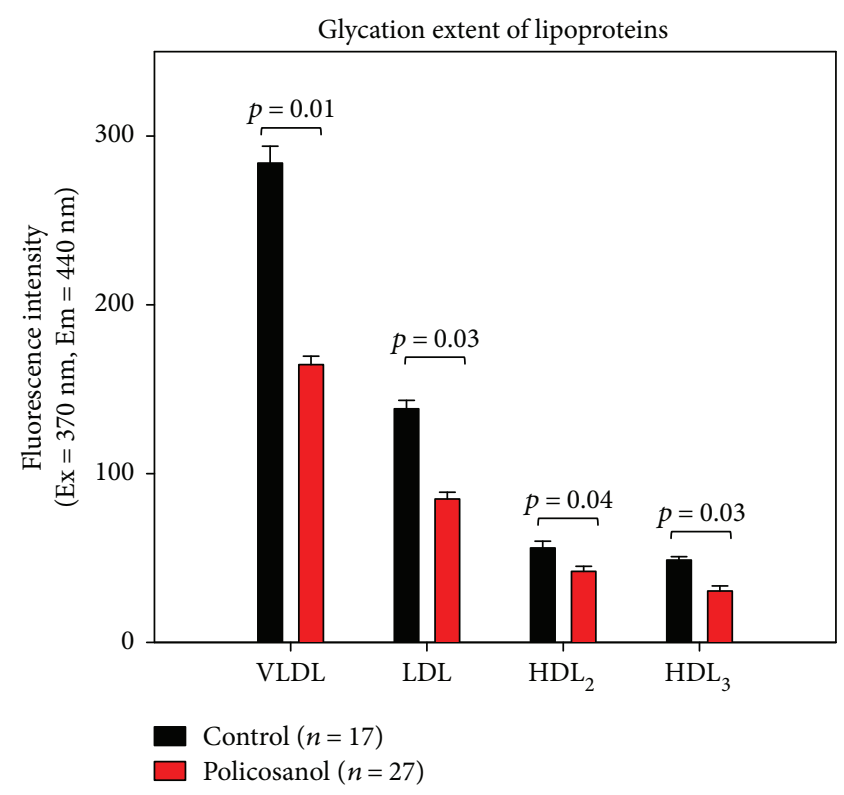

(a)

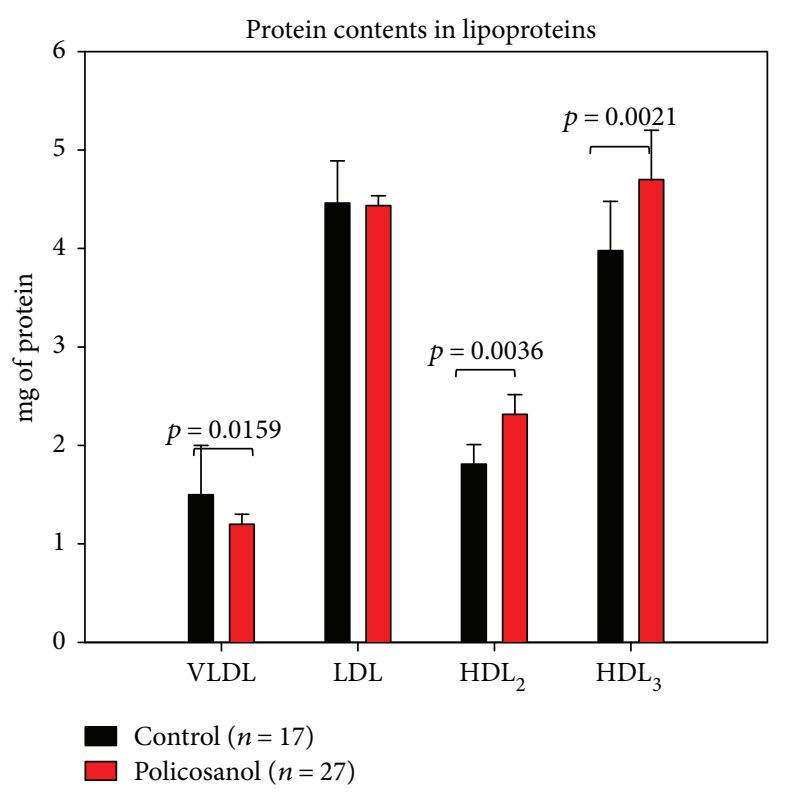

(b)

FIgURE 5: Glycation extent and total amounts of proteins in lipoproteins between groups after 8 weeks of policosanol consumption. (a) Fluorometric determination $(\mathrm{Ex}=370 \mathrm{~nm}, \mathrm{Em}=440 \mathrm{~nm}$ ) of glycation extent (bar represents the standard deviation). (b) Protein determination of individual lipoproteins (bar represents the standard deviation).

3.8. HDL Particle Size and Number. TEM image analysis revealed that the control and policosanol groups showed similar particle size after 8 weeks (photos of Figure 7). However, the particle number was significantly elevated up to 1.5fold in the PCO group compared to the control group (graphs of Figure 7).

3.9. Insulin Secretion. Under basal and high glucose conditions (final concentrations of 2.8 and $25 \mathrm{mM}$ in media), $\mathrm{HDL}_{2}$ from the control group induced $5 \%$ and $8 \%$ insulin secretion over 8 weeks in rat insulinoma cells (INS-1), as shown in Figure $8 . \mathrm{HDL}_{2}$ from the policosanol group caused a significant increase in insulin secretion under basal glucose and high glucose conditions compared to that at week 0 .

$\mathrm{HDL}_{3}$ from the policosanol group showed a significant enhancement of insulin secretion. In particular, $\mathrm{HDL}_{3}$ from the policosanol group caused a $14 \%$ increase in secretion compared to that at week 0 under high glucose conditions. Additionally, $\mathrm{HDL}_{3}$ from the policosanol group caused a $5 \%$ increase in secretion compared to that at week 0 under basal glucose conditions. Moreover, there was no significant difference observed in insulin secretion in control groups under basal and high glucose conditions.

3.10. Enhanced Cholesterol Efflux by rHDL-Containing Policosanol. As shown in Supplementary Figure 1A, cholesterol efflux activity increased from $24 \%$ to $29 \%$ as the policosanol content of rHDL significantly increased from 0.5 to $2.5 \mu \mathrm{g}$ in the presence of the same amount of $\mathrm{rHDL}(p=0.03$, under $56 \mu \mathrm{g}$ of apoA-I). Although there was no significant change $(p=0.06), 2.5 \mu \mathrm{g}$ of policosanol in the presence of a lower amount of rHDL (28 $\mu \mathrm{g}$ of apoA-I) more strongly enhanced cholesterol efflux activity than did $0.5 \mu \mathrm{g}$ of policosanol in the same amount of $\mathrm{rHDL}(28 \mu \mathrm{g}$ of apoA-I). However, $0.5 \mu \mathrm{g}$ of policosanol adequately enhanced cholesterol efflux activity compared with apoA-I alone, and a greater amount of policosanol $(2.5 \mu \mathrm{g})$ treatment resulted in a higher cholesterol efflux activity with the same amount of apoA-I in rHDL.

In addition to efflux activity, immunodetection revealed that uptake of apoA-I into macrophages was more facilitated (up to 60\%) as policosanol content increased with the same amount of apoA-I regardless of cAMP treatment, as shown in Supplementary Figure 1B. The expression level of ABCA1 also increased up to 2-fold upon PCO-rHDL treatment, especially in the presence of cAMP, whereas GAPDH expression as a loading control (total $10 \mu \mathrm{g}$ of protein from cell lysate) had no effect.

3.11. Improved Insulin Secretion by Policosanol. Rat INS-1 cells were incubated with rHDL-containing policosanol under basal $(2.8 \mathrm{mM}$ glucose in culture medium) and high glucose conditions ( $25 \mathrm{mM}$ glucose). After $48 \mathrm{hr}$ of incubation, rHDL-treated cells had insulin secretion levels of $20 \pm 2$ and $39 \pm 4 \mathrm{ng} / \mathrm{mL}$ under basal and high glucose conditions, respectively (Supplementary Figure 2). In contrast, cells treated with PCO-rHDL containing $28 \mu \mathrm{g}$ of apoA-I and policosanol (from 2.5 to $5 \mu \mathrm{g}$ ) showed elevated insulin secretion levels up to 90 and $98 \mathrm{ng} / \mathrm{mL}$, respectively. Cells treated with PCO-rHDL containing $56 \mu \mathrm{g}$ of apoA-I and policosanol (from 2.5 to $5 \mu \mathrm{g}$ ) showed elevated insulin secretion levels up to 116 and $127 \mathrm{ng} / \mathrm{mL}$ under basal and high glucose conditions, respectively. In the presence of the same amount of apoA-I, insulin secretion was elevated up to 1.4-fold depending on the policosanol content in rHDL (Supplementary Figure 2). 

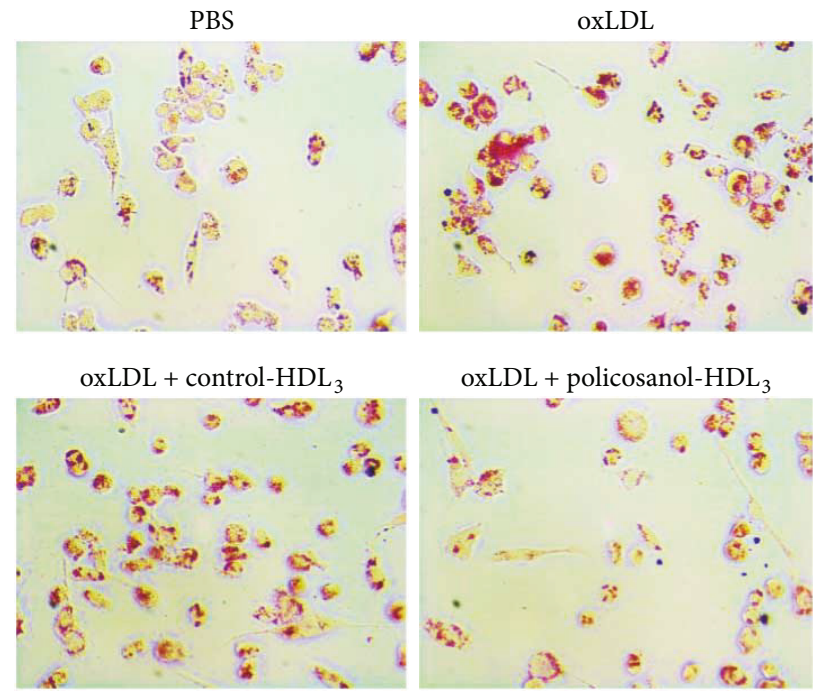

(a) THP-1 cell (oxLDL $\left.+\mathrm{HDL}_{3}\right)$

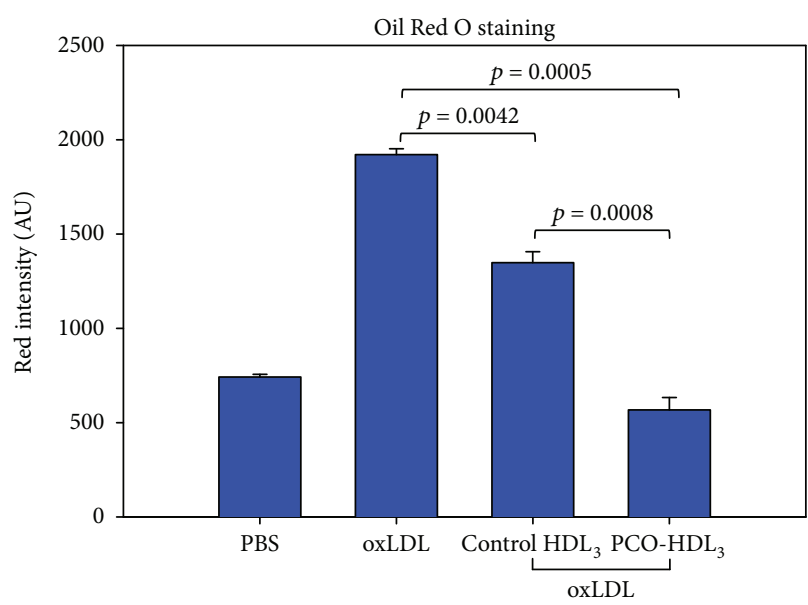

(b)

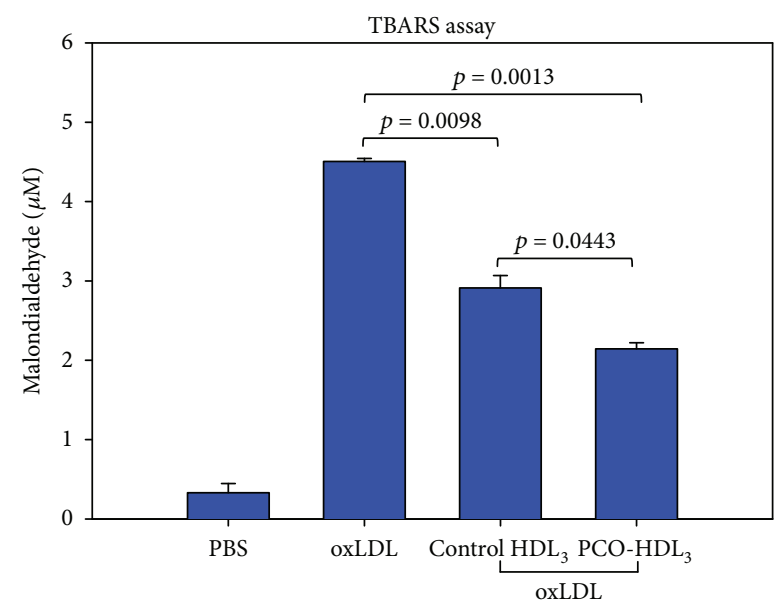

(c)

FIgURE 6: Comparison of oxLDL uptake into macrophages in the presence of $\mathrm{HDL}_{3}$ from each group. (a) Inhibition of oxLDL phagocytosis by HDL from each group, as visualized by Oil Red O staining. (b) Quantification of Oil Red O-stained area by computer-assisted morphometry. (c) Quantification of oxidized species in cell culture media using the TBARS method.

\section{Discussion}

In the current study, 8 weeks of policosanol consumption resulted in a reduction in blood pressure and visceral fat amount in healthy female subjects with prehypertension. The lowering effects of policosanol on blood pressure were accompanied by lowering of serum total cholesterol and triglyceride levels as well as increased HDL-C levels via inhibition of serum CETP activity (Table 1). One of the interesting findings of this study is that policosanol could enhance cholesterol efflux in a dose-dependent manner by stimulating the expression of ABCA-1 (Supplementary Figure 1). Cholesterol efflux is a key feature of HDL that exerts regression activity via removal of cholesterol from atherosclerotic plaques in the reverse cholesterol transport pathway. It has been reported that efflux activity is mainly dependent on the configuration of apoA-I [32]. Therefore, the current finding shows that policosanol enhanced cholesterol efflux synergistically with apoA-I. It has been suggested that the apoA-I configuration in discoidal HDL may be important for the recognition of cellular proteins as well as for interactions with specific lipid domains of the cell membrane. Our group previously reported that encapsulation of policosanol in $\mathrm{rHDL}$ caused a reduction in $\alpha$-helix content in apoA-I along with an increased exposure of Trp residues [7]. These configurational changes might increase the affinity between apoA-I and the lipid domain of ABCA-1 for enhancement of cholesterol efflux.

Native apoA-I and HDL can stimulate insulin secretion [33] and exert antidiabetic activity, whereas modified apoAI/HDL cannot. Native reconstituted HDL also displayed insulin secretion activity along with a wound-healing effect. Many studies on patients have reported that policosanol has efficacy in the treatment of hyperlipidemia, diabetes, and hypertension $[34,35]$, although the detailed molecular mechanism has not been elucidated. As there has been almost no study on the effects of policosanol on healthy subjects with hyperlipidemia and hypertension, this study 


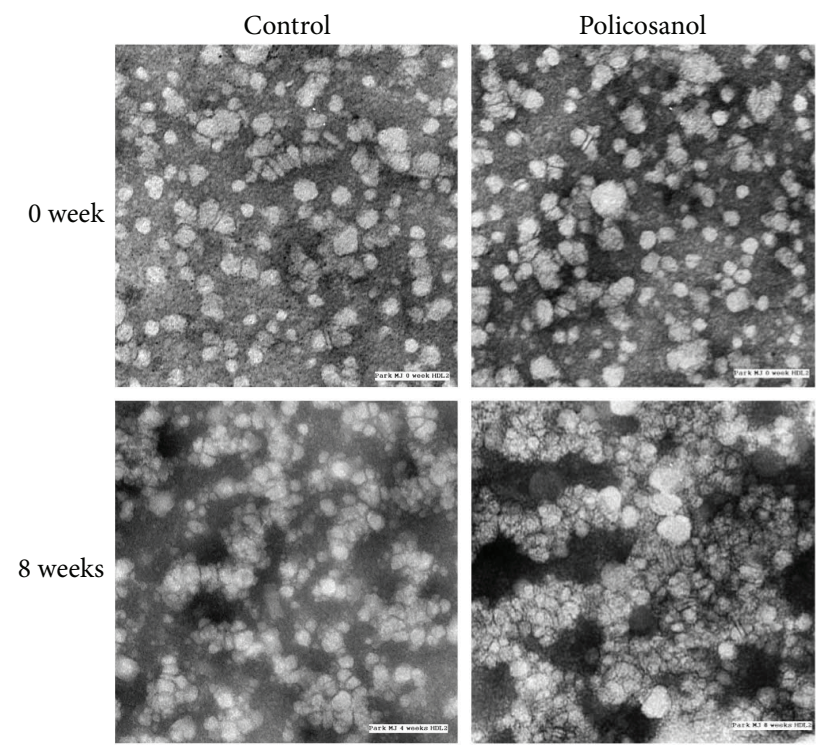

(a)

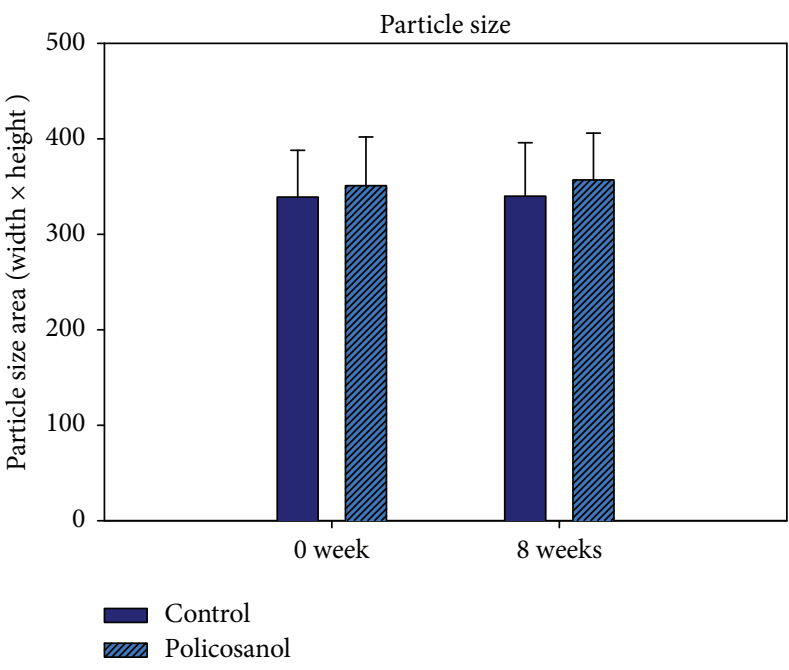

(b)

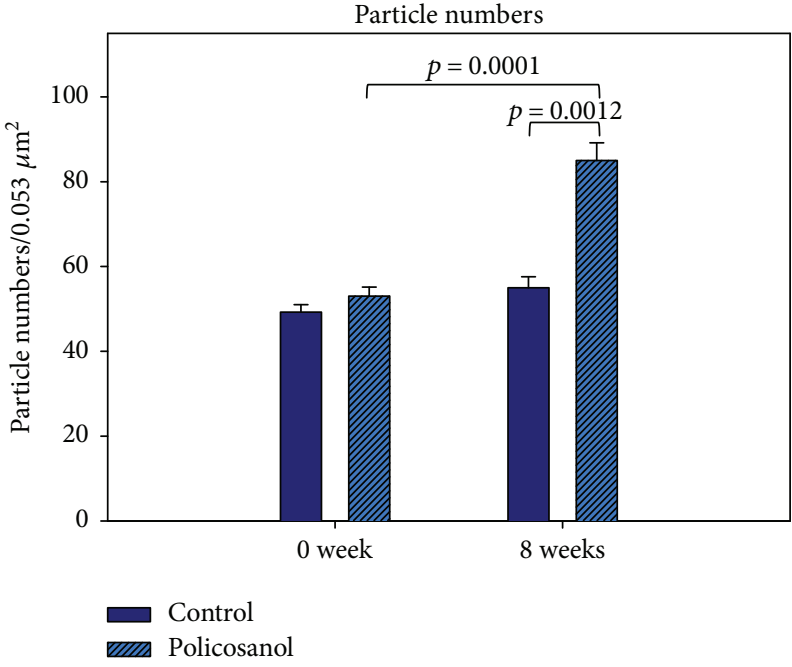

(c)

FIGURE 7: Electron microscopic observation of $\mathrm{HDL}_{2}$. (a) Illustrative image of negatively stained high-density lipoprotein 2 (HDL2) from control and policosanol group (electron microscopy). All micrographs are shown at a magnification of 40,000x. Scale bar corresponds to $100 \mathrm{~nm}$. (b) Graphs show measured width and length from 20 particles of HDL. (c) Histogram shows calculated particle numbers per $0.053 \mu \mathrm{m}^{2}$ area.

investigated the efficacy of policosanol in ordinary and healthy subjects with prehypertension.

A recent paper reported that hexacosanol reduces plasma and hepatic cholesterol by activation of adenosine $5^{\prime}$-monophosphate- (AMP-) activated protein kinase (AMPK) and suppression of sterol regulatory element-binding protein-2 in HepG2 and C57BL/6J mice [36]. It has been well known that AMPK activation activities were correlated with increased export of cholesterol and excretion of cholesterol [37]. Recently, AMPK activation enhances antiatherogenic effects of HDL with slightly lowering serum total cholesterol and body weight in $\mathrm{apoE}^{-/-}$mice [38]. Taken together, these papers make agreement that policosanol can enhance HDL functionality via AMPK activation and CETP inhibition.
CETP is an atherogenic factor, which is capable of degenerating HDL functionality and composition. Elevated CETP activity is associated with increased serum TG and TGenriched LDL levels. We previously reported that policosanol can potently inhibit human CETP in vitro $[7,8]$, similar to MK-0859 (anacetrapib), a CETP inhibitor from Merck (Kenilworth, NJ, USA). Supplementation with policosanol was previously shown to cause significant reduction of CETP activity in zebrafish plasma [8] and human plasma, especially in young and middle-aged healthy male subjects [9]. In the current report, female subjects also showed significant reduction of CETP activity and amount $(25 \%)$ in serum upon policosanol consumption. It has been well established that impairment of HDL functionality in patients with rheumatoid arthritis is associated with elevation of CETP activity 


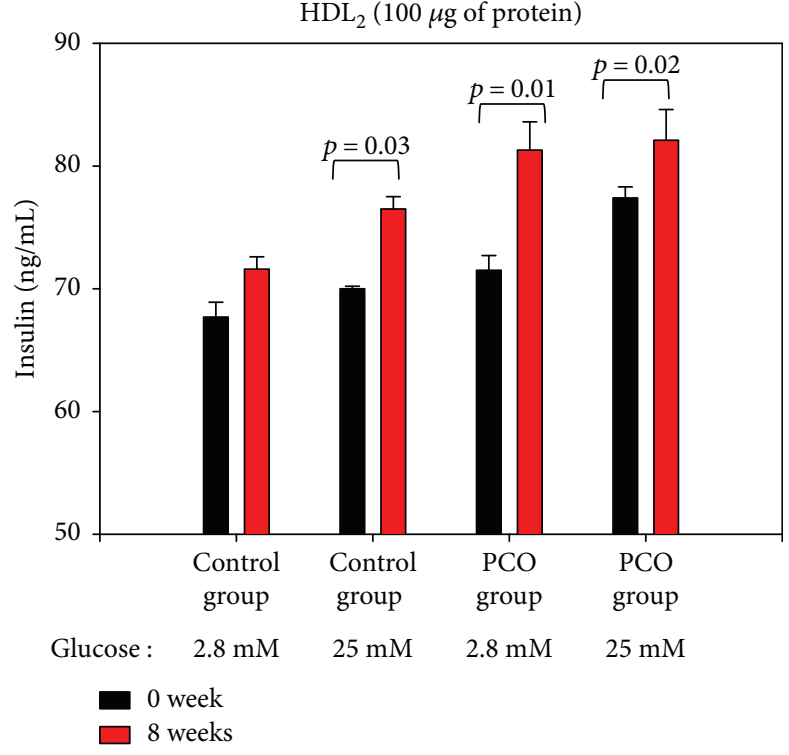

(a)

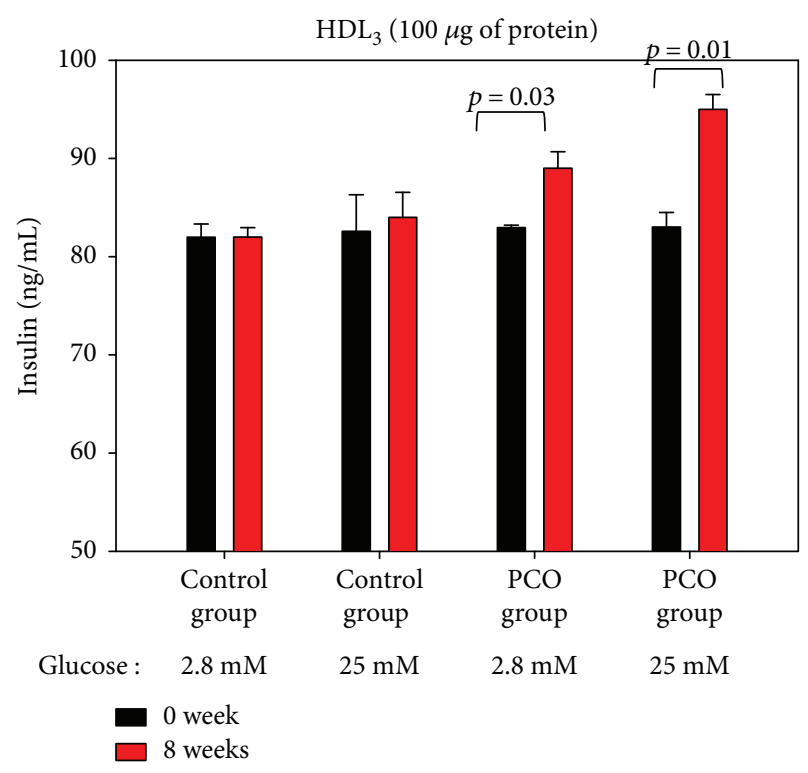

(b)

FIGURE 8: Insulin secretion activity of HDL from each group after 8 weeks of policosanol consumption. Rat insulinoma cells (INS-1) were incubated for $2 \mathrm{hr}$ in the presence of $\mathrm{HDL}_{2}$ and $\mathrm{HDL}_{3}$ (final $100 \mu \mathrm{g}$ of protein) at different glucose concentrations (final concentration of 2.8 or $25 \mathrm{mM}$ in culture medium). Insulin levels in medium were quantified using a radioimmunoassay kit. Results are expressed as the $\mathrm{m}$ ean \pm standard deviation (SD) from three independent experiments with duplicate samples.

and expression, as in our recent report [39]. Especially in an autoimmune disease state, such as rheumatoid arthritis, arterial stiffness was shown to be positively correlated with elevation of CETP activity [40]. Furthermore, CETP inhibition might be connected to lower visceral fat and antiobesity effect. Since higher CETP activity explains lower HDL-C in obese subjects, it has been suggested that plasma CETP levels may be regulated by the degree of total body fat accumulation [41].

The lipid profile most associated with exacerbation of metabolic syndrome is high TG levels, whereas low HDL-C levels are associated with high risk of insulin resistance [42] and systemic inflammation due to high visceral fat mass [43]. Policosanol consumption reduced the TG/HDL-C ratio and visceral fat amount (Table 1). In the current study, reduction of serum TG level was correlated with reduction of visceral fat mass in the policosanol group, and a Taiwanese study revealed that the serum TG level independently contributes to visceral fat amount [44]. Reduction of serum TG level could cause reduction of visceral fat mass. Nonobese patients with polycystic ovary syndrome show significantly higher serum TG and lower HDL-C levels along with 1.7 -fold increased visceral fat thickness [45] despite having normal BMI levels. It has been suggested that visceral fat thickness is negatively correlated with HDL-C level and positively correlated with serum TG level [46]. Further, the TG/HDL ratio can be a predictive marker for the success of antidiabetic medications following weight loss [47].

Systolic and diastolic blood pressures are positively correlated with visceral fat accumulation in premenopausal subjects [48]. These results are in good agreement with our previous report in which male subjects showed reduction of visceral fat mass and blood pressure after 8 weeks of policosanol consumption [9]. Nevertheless, the previous report involved many limitations such as small sample size, weak study design (absence of randomized, double-blinded, and placebocontrol), and diagnostic method of blood pressure.

Interestingly, antioxidant ability in plasma was elevated while oxidation of LDL was reduced upon policosanol consumption. PCO-rHDL also showed antioxidant ability against cupric ion treatment, as in our previous report $[7,8]$. Resistance of LDL oxidation to cupric ion (Figure 3) is associated with enhancement of HDL-associated paraoxonase activity (Figure 4). Higher paraoxonase activity is also associated with protection of LDL oxidation from lipid peroxidation [49]. The glycation extent of each lipoprotein fraction was reduced by policosanol consumption (Figure 5(a)), although protein content was similar to or higher than that of the control. The antiglycation effect of policosanol consumption (Figure 5) is well correlated with our previous report [7] that PCO-rHDL shows an inhibitory effect in vitro against fructose-mediated glycation of HDL. The antiglycation effect is known to be associated with vasorelaxation via improvement of atrial stiffness since AGEs are a proven marker of CVD, diabetes, and hypertension [50]. From a study with Chinese subjects, plasma AGE concentration was found to be positively correlated with pulse wave velocity from the carotid to femoral arteries [51]. More interestingly, the serum TG level was elevated under conditions of high plasma AGE content.

Interestingly, HDL functionality and particle numbers were elevated by policosanol, which is a new finding since there are no agents known to enhance apoA-I expression and HDL quality except curcumin [52]. Although several nutraceuticals have been reported to induce lipid-lowering [53] and arterial hypertension [54], the beneficial 
functions of lipid-free apoA-I and HDL can be impaired by oxidation and glycation, resulting in amyloid formation and aggregation [55, 56].

PCO-rHDL was taken up more by macrophages via upregulation of ABC-A1 (Supplementary Figure 1). Since dysfunction of ABCA1 is associated with a significant reduction in serum $\mathrm{HDL}$ levels, cholesterol efflux ability is positively correlated with apoA-I expression. A few angiotensin receptor blockers such as telmisartan and candesartan are known to interact with $\mathrm{ABC}$ transporters $[57,58]$. Our current results suggest that policosanol might regulate the expression of apolipoproteins and transporters, which are involved in reverse cholesterol transport. Apart from the functionality of HDL-C and structural changes in lipoproteins, we determine the levels of uric acid and aldosterone levels in both groups. Previous studies have linked the elevation of these biomarkers in blood which may increase the risk of causing hypertension [59-61]. These reports suggested a plausible role of biomarker uric acid and aldosterone levels. Hence, we examine the concentration of these biomarkers before and after policosanol consumption. Our results have demonstrated that the levels of uric acid and aldosterone were significantly reduced after consumption of policosanol for 8 weeks. We did not find any significant difference in the levels of these biomarkers in the placebo group. Clinically, these results imply that enhancement of HDL functionality is well correlated with improvement of blood pressure and visceral fat mass. These results are in good agreement with our previous report in which male subjects showed a reduction of visceral fat mass and blood pressure after 8 weeks of policosanol consumption [9]. The novelty of this study was the study design, notably participant's number, use of placebo group, recruitment of prehypertensive participants (SBP 120-139 mmHg, DBP $80-89 \mathrm{mmHg}$ ), three devices used to measuring blood pressure, and homogenous data with a considerable time period of therapy of policosanol. Additionally, this study measured the important biomarkers such as renin and aldosterone, which are previously known parameters that could associate with increased risk of hypertension and CVD. Therefore, the study result could determine the appropriateness and authenticity with respect to the study design, recruitment, and number of participants used in this study.

\section{Conclusions}

The present study tested the effects of policosanol on biomarkers of HDL functionality, including cellular cholesterol efflux, insulin secretion, CETP activity, paraoxonase activity, and apoA-I level, after 8 weeks of policosanol consumption. Improvement of HDL functionality was associated with lowered blood pressure and inhibition of CETP activity in female prehypertension subjects.
Abbreviations
BP: blood pressure
BMI: body mass index

CETP: cholesteryl ester transfer protein

TC: $\quad$ total cholesterol

TG: triglyceride

TP: $\quad$ total protein

HDL-C: high-density lipoprotein-cholesterol

HDL: high-density lipoprotein

LDL: low-density lipoprotein

VLDL: very low-density lipoprotein.

\section{Disclosure}

An earlier version of the paper has been presented in the 6th International Congress on Lipid \& Atherosclerosis (ICoLA 2017).

\section{Conflicts of Interest}

The authors declare no conflict of interests.

\section{Authors' Contributions}

Suk-Jeong Kim and Dhananjay Yadav performed the experiments. Jae-Yong Kim and Jae-Ryong Kim analyzed the data; Kyung-Hyun Cho wrote the manuscript and supervised all research for this study.

\section{Acknowledgments}

This work was supported by the Medical Research Center Program (2015R1A5A2009124) through the National Research Foundation (NRF), funded by the Ministry of Science, ICT and Future Planning of Korea. The authors thank Ki-Hoon Park and Seong-Min Kim for their technical assistance.

\section{Supplementary Materials}

Supplementary Figure 1: (A) cholesterol efflux activity of rHDL-containing apoA-I and policosanol. Macrophages were treated with radiolabeled cholesterol. The isotope amount of cholesterol taken up into cells was quantified, as detailed in the text; (B) immunodetection of apoA-I and ABCA-1 in cell lysate after treatment with rHDL. BI: band intensity. Supplementary Figure 2: insulin secretion activity of rHDL-containing policosanol. Rat insulinoma cells (INS-1) were incubated for $2 \mathrm{hr}$ in the presence of $\mathrm{rHDL}$ with or without policosanol (final concentration of $2.5-5 \mathrm{mg}$ in media) at different glucose concentrations (final concentration of 2.8 or $25 \mathrm{mM}$ in culture medium). Insulin levels in medium were quantified using a radioimmunoassay kit. Results are expressed as the mean \pm standard deviation (SD) from three independent experiments with duplicate samples. (Supplementary Materials)

\section{References}

[1] K.-A. Rye, C. A. Bursill, G. Lambert, F. Tabet, and P. J. Barter, "The metabolism and anti-atherogenic properties of HDL," Journal of Lipid Research, vol. 50, Supplement, pp. S195S200, 2009. 
[2] K.-H. Cho, "Biomedicinal implications of high-density lipoprotein: its composition, structure, functions, and clinical applications," BMB Reports, vol. 42, no. 7, pp. 393-400, 2009.

[3] S. Dragan, C. Serban, and M. Banach, "Can we change the functionality of HDL cholesterol with nonpharmacological and pharmacological agents?," Current Medicinal Chemistry, vol. 21, no. 25, pp. 2927-2946, 2014.

[4] I. Gouni-Berthold and H. K. Berthold, "Policosanol: clinical pharmacology and therapeutic significance of a new lipidlowering agent," American Heart Journal, vol. 143, no. 2, pp. 356-365, 2002.

[5] S. Fernández, M. Rosa, R. Gamez et al., "A pharmacological surveillance study of the tolerability of policosanol in the elderly population," The American Journal of Geriatric Pharmacotherapy, vol. 2, no. 4, pp. 219-229, 2004.

[6] M. Janikula, "Policosanol: a new treatment for cardiovascular disease? (Policosanol)," Alternative Medicine Review, vol. 7, no. 3, pp. 203-217, 2002.

[7] S.-M. Lim, J.-A. Yoo, E.-Y. Lee, and K.-H. Cho, "Enhancement of high-density lipoprotein cholesterol functions by encapsulation of policosanol exerts anti-senescence and tissue regeneration effects via improvement of anti-glycation, antiapoptosis, and cholesteryl ester transfer inhibition," Rejuvenation Research, vol. 19, no. 1, pp. 59-70, 2016.

[8] E.-Y. Lee, J.-A. Yoo, S.-M. Lim, and K.-H. Cho, “Anti-aging and tissue regeneration ability of policosanol along with lipid-lowering effect in hyperlipidemic zebrafish via enhancement of high-density lipoprotein functionality," Rejuvenation Research, vol. 19, no. 2, pp. 149-158, 2016.

[9] J.-Y. Kim, S.-M. Kim, S.-J. Kim, E.-Y. Lee, J.-R. Kim, and K.-H. Cho, "Consumption of policosanol enhances HDL functionality via CETP inhibition and reduces blood pressure and visceral fat in young and middle-aged subjects," International Journal of Molecular Medicine, vol. 39, no. 4, pp. 889899, 2017.

[10] R. M. Kaup, M. T. Khayyal, and E. J. Verspohl, “Antidiabetic effects of a standardized Egyptian rice bran extract," Phytotherapy Research, vol. 27, no. 2, pp. 264-271, 2013.

[11] H. K. Berthold, S. Unverdorben, R. Degenhardt, M. Bulitta, and I. Gouni-Berthold, "Effect of policosanol on lipid levels among patients with hypercholesterolemia or combined hyperlipidemia: a randomized controlled trial," JAMA, vol. 295, no. 19, pp. 2262-2269, 2006.

[12] F. Francini-Pesenti, D. Beltramolli, S. Dall'Acqua, and F. Brocadello, "Effect of sugar cane policosanol on lipid profile in primary hypercholesterolemia," Phytotherapy Research, vol. 22, no. 3, pp. 318-322, 2008.

[13] J. Gong, X. Qin, F. Yuan et al., "Efficacy and safety of sugarcane policosanol on dyslipidemia: a meta-analysis of randomized controlled trials," Molecular Nutrition \& Food Research, vol. 62 , no. 1, 2018.

[14] W. Li, X. Wang, L. Lu, and H. Li, "Discrepancy of blood pressure between the brachial artery and radial artery," World Journal of Emergency Medicine, vol. 4, no. 4, pp. 294297, 2013.

[15] J. E. Sharman and S. Laurent, "Central blood pressure in the management of hypertension: soon reaching the goal?," Journal of Human Hypertension, vol. 27, no. 7, pp. 405-411, 2013.

[16] S.-L. Chen, F.-F. Zhang, J. Xu et al., "Pulmonary artery denervation to treat pulmonary arterial hypertension: the single-center, prospective, first-in-man PADN-1 study (first- in-man pulmonary artery denervation for treatment of pulmonary artery hypertension)," Journal of the American College of Cardiology, vol. 62, no. 12, pp. 1092-1100, 2013.

[17] Yasmin and M. J. Brown, "Similarities and differences between augmentation index and pulse wave velocity in the assessment of arterial stiffness," QJM, vol. 92, no. 10, pp. 595-600, 1999.

[18] M. Butlin and A. Qasem, "Large artery stiffness assessment using SphygmoCor technology," Pulse, vol. 4, no. 4, pp. 180192, 2017.

[19] I. F. F. Benzie and J. J. Strain, "The ferric reducing ability of plasma (FRAP) as a measure of "antioxidant power": the FRAP assay,” Analytical Biochemistry, vol. 239, no. 1, pp. 7076, 1996.

[20] R. J. Havel, H. A. Eder, and J. H. Bragdon, "The distribution and chemical composition of ultracentrifugally separated lipoproteins in human serum," The Journal of Clinical Investigation, vol. 34, no. 9, pp. 1345-1353, 1955.

[21] M. A. K. Markwell, S. M. Haas, L. L. Bieber, and N. E. Tolbert, "A modification of the Lowry procedure to simplify protein determination in membrane and lipoprotein samples," Analytical Biochemistry, vol. 87, no. 1, pp. 206-210, 1978.

[22] M. S. Blois, "Antioxidant determinations by the use of a stable free radical," Nature, vol. 181, no. 4617, pp. 1199-1200, 1958.

[23] J. D. McPherson, B. H. Shilton, and D. J. Walton, "Role of fructose in glycation and cross-linking of proteins," Biochemistry, vol. 27, no. 6, pp. 1901-1907, 1988.

[24] K.-H. Cho, "Synthesis of reconstituted high density lipoprotein (rHDL) containing apoA-I and apoC-III: the functional role of apoC-III in rHDL," Molecules and Cells, vol. 27, no. 3, pp. 291-297, 2009.

[25] H. W. Eckerson, C. M. Wyte, and B. La Du, "The human serum paraoxonase/arylesterase polymorphism," American Journal of Human Genetics, vol. 35, no. 6, pp. 1126-1138, 1983.

[26] K.-H. Park, D.-G. Shin, J.-R. Kim, J.-H. Hong, and K.-H. Cho, "The functional and compositional properties of lipoproteins are altered in patients with metabolic syndrome with increased cholesteryl ester transfer protein activity," International Journal of Molecular Medicine, vol. 25, no. 1, pp. 129-136, 2010.

[27] K.-H. Park, W. Jang, K.-Y. Kim, J.-R. Kim, and K.-H. Cho, "Fructated apolipoprotein A-I showed severe structural modification and loss of beneficial functions in lipid-free and lipid-bound state with acceleration of atherosclerosis and senescence," Biochemical and Biophysical Research Communications, vol. 392, no. 3, pp. 295-300, 2010.

[28] B. F. Asztalos, M. de la Llera-Moya, G. E. Dallal, K. V. Horvath, E. J. Schaefer, and G. H. Rothblat, "Differential effects of HDL subpopulations on cellular ABCA1- and SR-BI-mediated cholesterol efflux," Journal of Lipid Research, vol. 46, no. 10, pp. 2246-2253, 2005.

[29] K.-H. Park, J.-Y. Kim, I. Choi, J.-R. Kim, K. C. Won, and K.-H. Cho, "Fructated apolipoprotein A-I exacerbates cellular senescence in human umbilical vein endothelial cells accompanied by impaired insulin secretion activity and embryo toxicity," Biochemistry and Cell Biology, vol. 94, no. 4, pp. 337-345, 2016.

[30] J.-H. Yoon and K.-H. Cho, "A point mutant of apolipoprotein A-I (V156K) showed enhancement of cellular insulin secretion and potent activity of facultative regeneration in zebrafish," Rejuvenation Research, vol. 15, no. 3, pp. 313-321, 2012.

[31] H. H. Lee, J. E. Park, I. H. Choi, and K. H. Cho, "Enhanced functional and structural properties of high-density lipoproteins 
from runners and wrestlers compared to throwers and lifters," BMB Reports, vol. 42, no. 9, pp. 605-610, 2009.

[32] L. Á. Cuellar, E. D. Prieto, L. V. Cabaleiro, and H. A. Garda, "Apolipoprotein A-I configuration and cell cholesterol efflux activity of discoidal lipoproteins depend on the reconstitution process," Biochimica et Biophysica Acta (BBA) - Molecular and Cell Biology of Lipids, vol. 1841, no. 1, pp. 180-189, 2014.

[33] A. von Eckardstein and C. Widmann, "High-density lipoprotein, beta cells, and diabetes," Cardiovascular Research, vol. 103, no. 3, pp. 384-394, 2014.

[34] O. Torres, A. J. Agramonte, J. Illnait, R. M. Ferreiro, L. Fernandez, and J. C. Fernandez, "Treatment of hypercholesterolemia in NIDDM with policosanol," Diabetes Care, vol. 18, no. 3, pp. 393-397, 1995.

[35] K. Xu, X. Liu, Y. Li et al., "Safety and efficacy of policosanol in patients with high on-treatment platelet reactivity after drug-eluting stent implantation: two-year follow-up results," Cardiovascular Therapeutics, vol. 34, no. 5, pp. 337-342, 2016.

[36] J. H. Lee, Y. Jia, T. T. Thach et al., "Hexacosanol reduces plasma and hepatic cholesterol by activation of AMPactivated protein kinase and suppression of sterol regulatory element-binding protein-2 in HepG2 and C57BL/6J mice," Nutrition Research, vol. 43, pp. 89-99, 2017.

[37] M. D. Fullerton, R. J. Ford, C. P. McGregor et al., "Salicylate improves macrophage cholesterol homeostasis via activation of Ampk," Journal of Lipid Research, vol. 56, no. 5, pp. 10251033, 2015.

[38] A. Ma, J. Wang, L. Yang, Y. An, and H. Zhu, "AMPK activation enhances the anti-atherogenic effects of high density lipoproteins in apoE $^{-/-}$mice," Journal of Lipid Research, vol. 58, no. 8, pp. 1536-1547, 2017.

[39] J.-Y. Kim, E.-Y. Lee, J. K. Park, Y. W. Song, J.-R. Kim, and K.-H. Cho, "Patients with rheumatoid arthritis show altered lipoprotein profiles with dysfunctional high-density lipoproteins that can exacerbate inflammatory and atherogenic process," PLoS One, vol. 11, no. 10, article e0164564, 2016.

[40] E. Botta, T. Meroño, C. Saucedo et al., "Associations between disease activity, markers of HDL functionality and arterial stiffness in patients with rheumatoid arthritis," Atherosclerosis, vol. 251, pp. 438-444, 2016.

[41] T. Arai, S. Yamashita, K.-i. Hirano et al., "Increased plasma cholesteryl ester transfer protein in obese subjects. A possible mechanism for the reduction of serum HDL cholesterol levels in obesity," Arteriosclerosis, Thrombosis, and Vascular Biology, vol. 14, no. 7, pp. 1129-1136, 1994.

[42] M. Zhou, L. Zhu, X. Cui et al., “The triglyceride to high-density lipoprotein cholesterol (TG/HDL-C) ratio as a predictor of insulin resistance but not of $\beta$ cell function in a Chinese population with different glucose tolerance status," Lipids in Health and Disease, vol. 15, no. 1, p. 104, 2016.

[43] L. Catrysse and G. van Loo, "Inflammation and the metabolic syndrome: the tissue-specific functions of NF- $\kappa \mathrm{B}$," Trends in Cell Biology, vol. 27, no. 6, pp. 417-429, 2017.

[44] C. Y. Huang, H. L. Huang, K. C. Yang et al., "Serum triglyceride levels independently contribute to the estimation of visceral fat amount among nondiabetic obese adults," Medicine, vol. 94, no. 23, article e965, 2015.

[45] B. Yildirim, N. Sabir, and B. Kaleli, "Relation of intraabdominal fat distribution to metabolic disorders in nonobese patients with polycystic ovary syndrome," Fertility and Sterility, vol. 79, no. 6, pp. 1358-1364, 2003.
[46] Y. Matsuzawa, I. Shimomura, T. Nakamura, Y. Keno, K. Kotani, and K. Tokunaga, "Pathophysiology and pathogenesis of visceral fat obesity," Obesity Research, vol. 3, no. S2, pp. 187s-194s, 1995.

[47] G. P. S. Shantha, A. A. Kumar, S. Kahan, P. K. Irukulla, and L. J. Cheskin, "Triglyceride/HDL ratio as a screening tool for predicting success at reducing anti-diabetic medications following weight loss," PLoS One, vol. 8, no. 7, article e69285, 2013.

[48] H. Kanai, Y. Matsuzawa, K. Kotani et al., "Close correlation of intra-abdominal fat accumulation to hypertension in obese women," Hypertension, vol. 16, no. 5, pp. 484-490, 1990.

[49] K. R. Feingold and C. Grunfeld, "Effect of inflammation on HDL structure and function," Current Opinion in Lipidology, vol. 27, no. 5, pp. 521-530, 2016.

[50] M. McNulty, A. Mahmud, and J. Feely, "Advanced glycation end-products and arterial stiffness in hypertension," American Journal of Hypertension, vol. 20, no. 3, pp. 242-247, 2007.

[51] C. Y. Liu, Q. F. Huang, Y. B. Cheng et al., "A comparative study on skin and plasma advanced glycation end products and their associations with arterial stiffness," Pulse, vol. 4, no. 4, pp. 208 218, 2017.

[52] S. Ganjali, C. N. Blesso, M. Banach, M. Pirro, M. Majeed, and A. Sahebkar, "Effects of curcumin on HDL functionality," Pharmacological Research, vol. 119, pp. 208-218, 2017.

[53] A. F. G. Cicero, A. Colletti, G. Bajraktari et al., "Lipid-lowering nutraceuticals in clinical practice: position paper from an International Lipid Expert Panel," Nutrition Reviews, vol. 75, no. 9, pp. 731-767, 2017.

[54] C. Serban, A. Sahebkar, S. Ursoniu, F. Andrica, and M. Banach, "Effect of sour tea (Hibiscus sabdariffa L.) on arterial hypertension: a systematic review and meta-analysis of randomized controlled trials," Journal of Hypertension, vol. 33, no. 6, pp. 1119-1127, 2015.

[55] C. L. Teoh, M. D. W. Griffin, and G. J. Howlett, "Apolipoproteins and amyloid fibril formation in atherosclerosis," Protein \& Cell, vol. 2, no. 2, pp. 116-127, 2011.

[56] M. Das, C. J. Wilson, X. Mei, T. E. Wales, J. R. Engen, and O. Gursky, "Structural stability and local dynamics in disease-causing mutants of human apolipoprotein A-I: what makes the protein amyloidogenic?," Journal of Molecular Biology, vol. 428, no. 2, pp. 449-462, 2016.

[57] N. Ishiguro, K. Maeda, A. Saito et al., "Establishment of a set of double transfectants coexpressing organic anion transporting polypeptide $1 \mathrm{~B} 3$ and hepatic efflux transporters for the characterization of the hepatobiliary transport of telmisartan acylglucuronide," Drug Metabolism and Disposition, vol. 36, no. 4, pp. 796-805, 2008.

[58] J. Weiss, A. Sauer, N. Divac et al., "Interaction of angiotensin receptor type 1 blockers with ATP-binding cassette transporters," Biopharmaceutics \& Drug Disposition, vol. 31, no. 2-3, pp. 150-161, 2010.

[59] T. S. Perlstein, O. Gumieniak, G. H. Williams et al., "Uric acid and the development of hypertension: the normative aging study," Hypertension, vol. 48, no. 6, pp. 1031-1036, 2006.

[60] I. Saito, T. Saruta, K. Kondo et al., "Serum uric acid and the renin-angiotensin system in hypertension," Journal of the American Geriatrics Society, vol. 26, no. 6, pp. 241-247, 1978.

[61] V. Xanthakis and R. S. Vasan, "Aldosterone and the risk of hypertension," Current Hypertension Reports, vol. 15, no. 2, pp. 102-107, 2013. 


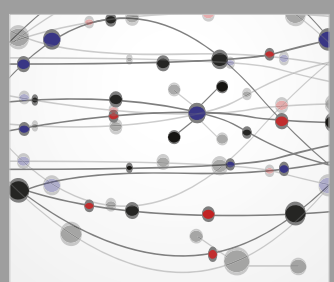

The Scientific World Journal
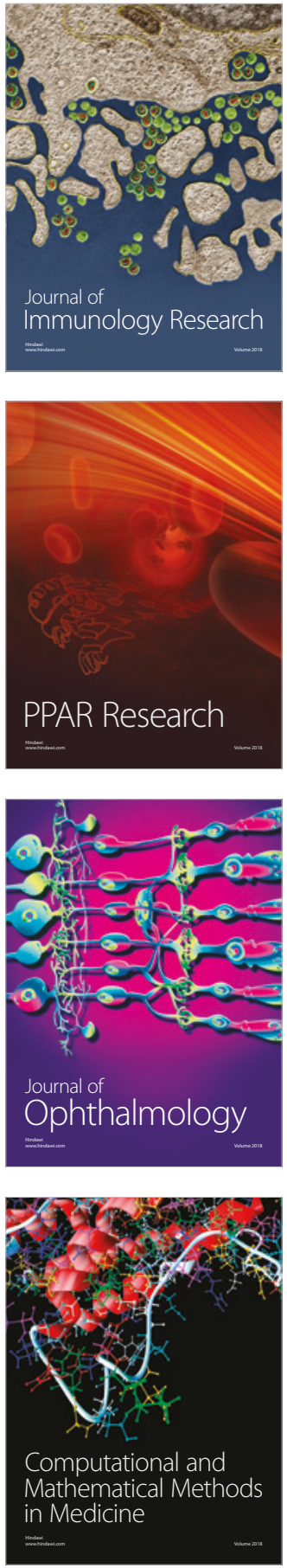

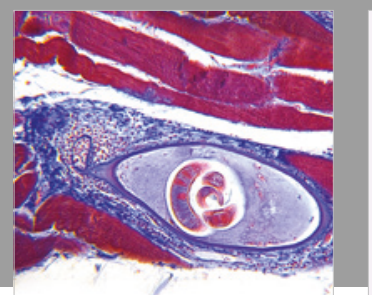

Gastroenterology Research and Practice

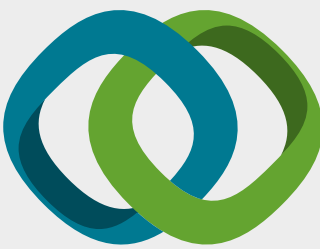

\section{Hindawi}

Submit your manuscripts at

www.hindawi.com
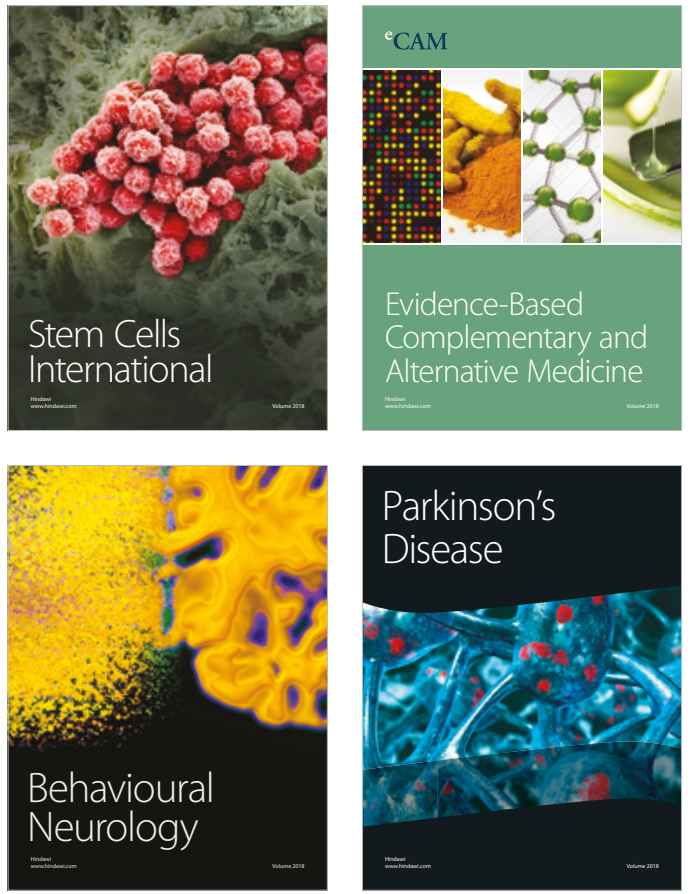

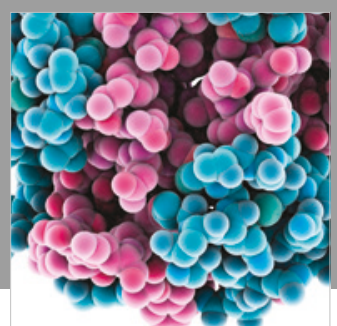

ournal of

Diabetes Research

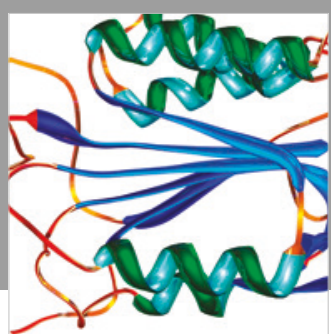

Disease Markers
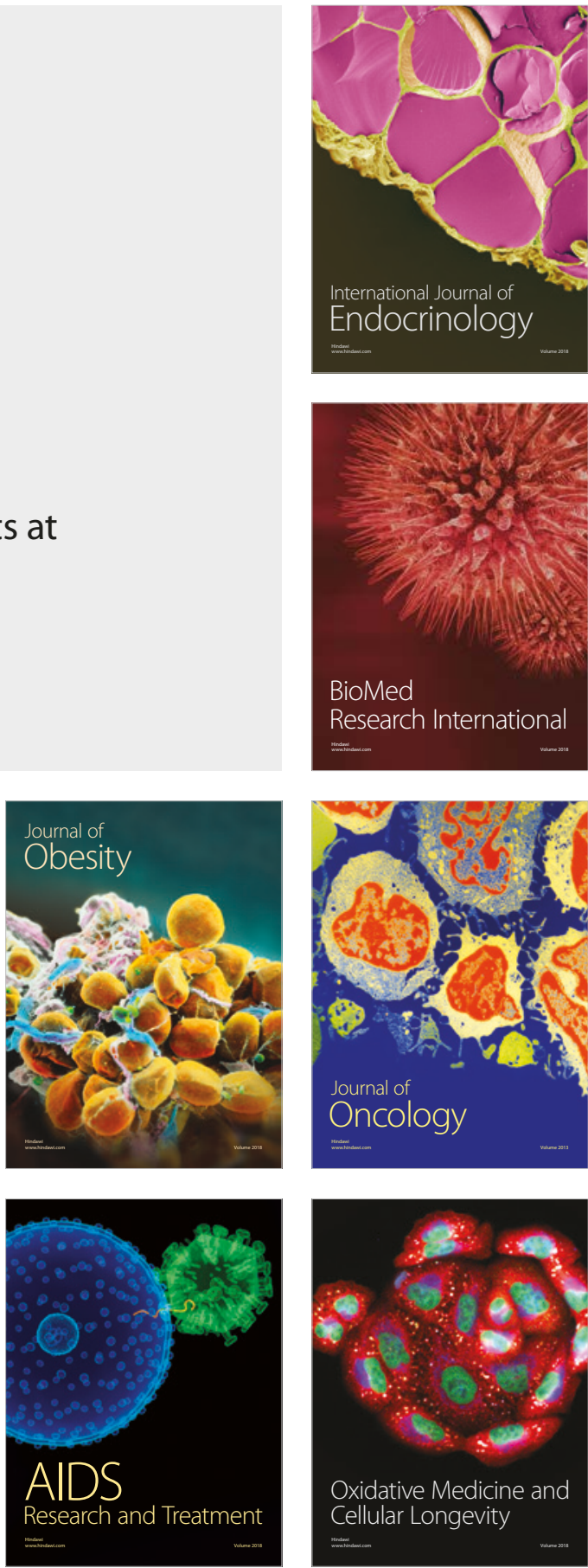